\title{
VOCES Y ACEPCIONES NUEVAS EN EL DRAE 1837*
}

\author{
NEW WORDS AND NEW MEANINGS IN THE DRAE 1837
}

\author{
Carolina Julià Luna \\ Universidad Nacional de Educación a Distancia (UNED) \\ cjulia@flog.uned.es
}

Recibido: 05/12/2018

Aceptado: 14/02/2019

\begin{abstract}
Resumen
El objetivo principal de esta investigación es el examen de las características formales, semánticas, etimológicas y documentales de las voces y acepciones incorporadas en la octava edición del DRAE publicada en 1837. A partir del estudio lexicológico y documental de las adiciones se pretende dar cuenta de que, a pesar de ser una de las ediciones de la historia de la lexicografía académica menos destacadas del siglo XIX, el trabajo que refleja la selección de voces y definiciones añadidas es una muestra de la voluntad de mantener el compromiso que la Corporación tenía con el público al que llegaba la obra y también de la necesidad de mantenerla actualizada con el fin de que el diccionario reflejara la lengua de la época.
\end{abstract}

PALABRAS CLAVE: DRAE, lexicografía, siglo XIX, nuevas voces, nuevas acepciones

\begin{abstract}
The main aim of this research is the analysis of the formal, semantic, etymological and documentary characteristics of the new words and meanings in the eighth edition of the DRAE published in 1837. From the lexicological and documentary study of the words and meanings it is intended to demonstrate that, despite being one of the less prominent editions of the nineteenth century, the work of selecting new voices and meanings shows the will to maintain the commitment that the Corporation had with the public that arrived the dictionary and also the need to keep it updated in order that the dictionary reflects the language of that time.
\end{abstract}

KEY WORDS: DRAE, lexicography, 19th century, new entries, new definitions

\footnotetext{
* Esta investigación ha sido posible gracias a la ayuda obtenida para el proyecto "Historia interna del Diccionario de la lengua castellana de la Real Academia Española en el siglo XIX (1817-1852)" (n. de referencia FFI201451904-P), financiado por el Ministerio de Economía y Competitividad, y a la ayuda para el proyecto "Grup de lexicografía i diacronía" (SGR2017-1251) del Comissionat per Universitats i Recerca de la Generalitat de Catalunya.
}

Para citar este artículo / To cite this article: Julià Luna, Carolina. Voces y acepciones nuevas en el DRAE 1837. Azorín, Dolores; Clavería, Gloria y Jiménez Ríos, Enrique (Eds.): ELUA: El diccionario de la Academia y su tiempo: lexicografía, lengua y sociedad en la primera mitad del siglo XIX, Anexo V, págs. 143-180.

Enlace/Link: http://dx.doi.org/10.14198/ELUA2019.ANEXO5.06 


\section{INTRODUCCIÓN}

De entre todas las ediciones del diccionario usual que la Real Academia publicó en el siglo XIX, la octava resulta una de las menos estudiadas o analizadas por cuanto ofrece un número reducido de cambios y estos son de menor importancia, según se deduce de la lectura del prólogo de la obra (Alvar Ezquerra 1983, 1985) y de las investigaciones realizadas sobre los diccionarios académicos decimonónicos (Álvarez de Miranda 2001, Clavería 2016). Por ello, quizá, de las diez ediciones publicadas a lo largo de la centuria del ochocientos $(1803,1817,1822,1832,1837,1843,1852,1869,1884,1899)$, esta es la que menos ha llamado la atención de los investigadores ${ }^{1}$, ya que no aporta novedades tan relevantes en la historia de la lexicografía decimonónica como otras, entre las que destacan, la decimosegunda (Garriga 2001) y la decimotercera (Clavería 2003).

Alvar Ezquerra (1983: 221, 1985: 41, nota 54), en sus trabajos sobre los prólogos de las ediciones, casi no la menciona; Álvarez de Miranda (2001: 54), por su parte, la describe como una edición que no presenta novedades importantes; y Clavería (2016: 109) caracteriza los trabajos de desarrollo del aumento y de la enmienda de este diccionario como labores de "poco calado" si se comparan con las de otras ediciones. Las investigaciones de esta última autora permiten advertir que muy probablemente la poca importancia que define a esta obra se debe a la celeridad con la que se trabajó para su publicación, que ve la luz tan solo cinco años después de que su antecesora lo hiciera. Según la revisión que hizo Vicente Salvá de la obra para su Diccionario de 1838 y la segunda edición del mismo en $1841^{2}$ — con la que inició su contribución a la historia de la lexicografía siguiendo el movimiento francés que se basaba en la publicación de la corrección de la obra académica (Azorín y Baquero 1994-1995: 13)—, la octava edición presenta problemas que revelan "inconsistencias en el método" de trabajo lexicográfico desarrollado desde 1832 hasta su publicación (Álvarez de Miranda 2003: 105). A las críticas de Salvá podrían sumarse las que aparecen en otra obra lexicográfica no académica publicada también en París por José René Masson. Se trata de la segunda edición de 1842 titulada Diccionario de la lengua castellana, por la Academia Española; nueva edición hecha según las dos últimas de Madrid en la que el autor critica duramente algunas de las decisiones que la Corporación toma para la corrección y actualización de la octava edición como, por ejemplo, la supresión de los participios pasivos (Trujillo-González 2013: 15). En Clavería (2016: 109-110), se detalla el proceso de corrección, aumento y enmienda que acontece desde mayo de 1833 hasta agosto de 1837 a partir de la información que incluyen las actas como una etapa en la que "no trasciende ningún tipo de discusión o información interesante".

A pesar de esta ausencia de informaciones relevantes en las Actas y de la falta de cambios importantes en la octava edición que han evidenciado los trabajos sobre la lexicografía

1 Si se recurre, por ejemplo, a la consulta del $D E C H$, una obra que, según Clavería (2016: 48), contiene 2382 voces cuya primera documentación se hallaba en alguna de las ediciones del DRAE del siglo XIX, se observa que el diccionario etimológico no contienen ningún dato sobre la octava edición, de lo que se deduce que no se contempló como fuente de referencia.

2 Se trata de las siguientes obras (Álvarez de Miranda 2003: 99): Diccionario de la lengua castellana por la Real Academia Española reimpreso de la octava edición publicada en Madrid en 1837, con algunas mejoras, por Don Vicente Salvá, París, Librería de D. Vicente Salvá, 1838, XX+994 págs. y Diccionario de la lengua castellana por la Real Academia Española reimpreso de la octava edición publicada en Madrid en 1837, con algunas mejoras, por Don Vicente Salvá. Segunda edición, mucho más correcta que la primera, según se demuestra a continuación de la Advertencia preliminar. París, Librería de D. Vicente Salvá, 1841, XX+994 págs. 
académica del siglo XIX, debe tenerse en cuenta que no es una edición que haya trascendido sin modificación alguna. Un análisis detallado de sus páginas, desde el Prólogo hasta el Suplemento, refleja que se trabajó en la mejora y corrección de diferentes aspectos propios tanto de la macroestructura como de la microestructura de la obra atendiendo a las necesidades del momento. A partir del estudio lexicológico y documental de las nuevas incorporaciones (lemas y acepciones), en el presente artículo se pretende dar cuenta de que, a pesar de no ser una edición tan relevante como otras de su centuria (como las de 1803 y 1884, por ejemplo), no debe despreciarse el trabajo que los lexicógrafos llevaron a cabo en ella porque es una muestra de la voluntad de continuar con el compromiso de la Corporación hacia el público al que llegaba la obra y de la necesidad de mantenerla al día según los cambios lingüísticos de la época - especialmente en lo que a ortografía se refiere- y que constituyen el reflejo del carácter prescriptivo de la Academia (Contreras 2003).

En la presente investigación se lleva a cabo un análisis centrado en el aumento del lemario y de acepciones incorporadas a los lemas ya existentes en la edición anterior. Así, se dejan las cuestiones propias de la microestructura para investigaciones futuras, un tema que, a juzgar por los datos que menciona Álvarez de Miranda (2003) a partir del estudio de las dos primeras obras que Salvá aporta a la lexicografía moderna monolingüe, debería examinarse con mayor detenimiento de lo que se ha hecho hasta el momento.

\section{EL PRÓLOGO: ALGUNAS MEJORAS E INNOVACIONES}

En el Prólogo de 1837, que ocupa muy poco en comparación con el de otras ediciones ${ }^{3}$, se admite que se sigue el contenido de la edición anterior y que se han incorporado "mejoras notables" en tres aspectos fundamentales: por un lado, el aumento de voces castellanas; por otro lado, la ampliación de correspondencias latinas; $\mathrm{y}$, finalmente, la corrección de definiciones que en la edición anterior podían resultar oscuras y poco exactas y se han ampliado o reducido. Para esta investigación interesa, especialmente, el hecho de que lo primero que se destaca en el prólogo es el aumento de voces castellanas, pues muchas de las incorporaciones que se han incluido en esta edición, como se verá en los apartados siguientes, son préstamos, entre los que destacan notablemente los de procedencia francesa. De igual modo, la referencia a los cambios en las definiciones es relevante y demuestra la voluntad de mejorar el Diccionario edición tras edición, un tema recurrente en los prólogos de la primera edición del siglo XIX (Rodríguez Barcia 2013: 31).

Asimismo, se da cuenta de que una de las innovaciones más importantes que incluye la octava edición se expresa en materia de ortografía: "ha creído oportuno la Academia sustituir la $\mathrm{j}$ á la g fuerte en gran número de voces que hasta aquí se habían escrito con la segunda de estas consonantes" (Prólogo DRAE 1837: 1). Para finalizar, en las palabras introductorias a la obra, la Corporación recuerda uno de los principales cometidos de la obra, que es dar cabida a las palabras que son de uso común y, por ello, justifica la ausencia de aquellos términos técnicos que son de origen clásico por no pertenecer al caudal de los idiomas vulgares. Con ello, quizá, se pretendía excusar y justificar la ausencia de voces especializadas y propias del lenguaje técnico y científico, un ámbito que, sin embargo, como se podrá comprobar en el presente análisis, está

3 El Prólogo de la octava edición ocupa 54 líneas mientras que el de su antecesora (DRAE 1832) y sucesora (DRAE 1843) lo doblan, pues la séptima ocupa poco más de 100 líneas y el de la novena, 117. 
bien representado en el conjunto de lemas que conforman el aumento de esta edición (el 40\% de las voces y acepciones que se incorporan pertenecen a alguna ciencia o arte, vid. el § 4.2.2.).

Después de esta breve advertencia, se incluye la lista de los académicos y la explicación de las abreviaturas a la que sigue la descripción del modo en el que el usuario debe buscar las voces pluriverbales. Destaca el hecho de que esta información aparezca fuera del prólogo cuando en la de 1832 lo hacía al final de este. Esta cuestión, la del lugar que ocupa la información sobre las formaciones multiverbales, es el único aspecto que Alvar Ezquerra (1983: 221) destaca sobre esta edición: "a partir de la octava edición 1837 ocuparon [entiéndase las normas para la colocación de las formaciones pluriverbales] un espacio independiente entre las notas preliminares de la obra, si bien sin encabezamiento ninguno hasta la undécima edición (1869)".

Debido a la brevedad y simpleza del Prólogo de esta edición en lo que respecta al tipo de léxico sobre el que más se ha trabajado, para investigar el aumento de voces no se puede partir de los datos que este contiene, a diferencia de lo que sucede en otras ediciones en las que las páginas preliminares aportan pistas importantes para saber cuáles han sido las áreas en las que la Corporación se ha detenido más (p. e. en las páginas iniciales del DRAE 1832 se menciona la especial atención dedicada a las ciencias naturales). Sin embargo, se deben tomar en cuenta dos afirmaciones relacionadas con la voluntad de seguir incorporando léxico de uso común y la voluntad de no incluir términos de origen clásico.

\section{ABREVIATURAS}

La lista de abreviaturas no se ve afectada por cambios relevantes, solo ajustes en algunos casos que implican, en la mayoría de ocasiones, ampliación o reducción de una letra de la abreviatura que había en la edición anterior o una corrección ortográfica relacionada con los cambios que se habían anunciado en el Prólogo. Se mantiene, por tanto, el número de abreviaturas mencionadas (142) y se corrigen 7 de ellas, que son las que se recogen en la tabla 1:

\begin{tabular}{|l|l|l|}
\hline \multicolumn{1}{|c|}{ DRAE 1832 } & \multicolumn{1}{c|}{ DRAE 1837 } & \multicolumn{1}{c|}{ Significado } \\
\hline Cerrag. & Cerraj. & Cerrajería \\
\hline Diop. ó Diopr. & Diop. ó Diopt. & Voz de la Dióptrica \\
\hline$f$. ó fr. & $f r$. & Frase \\
\hline fr. $p$. & $f . p$. & Frase proverbial \\
\hline Ortog. & Ortogr. & Ortografía \\
\hline p. Ast. de Santil. & p. Ast. de Santill. & Provincial de Astúrias de Santillana \\
\hline p. Mur. & p. Murc. & Provincial de Murcia \\
\hline part. conj. & part. conjunt. & Partícula conjuntiva \\
\hline
\end{tabular}

Tabla 1. Cambios en las abreviaturas del DRAE 1837.

Además de estos cambios, debe mencionarse la aparición de una abreviatura de carácter diatópico que no se halla en la lista y que aparece en la voz volanta del Suplemento. Esta palabra se marca como prov. de la Habana, una marca interesante desde el punto de vista de la incorporación de americanismos a la historia del $D R A E$, puesto que no es habitual antes de la edición 
de 1884. En palabras de Seco (1988: 91-92), no es hasta esta obra, la decimosegunda, cuando se observa un "paulatino aumento en la cuota americana [...] en cuyo prólogo la Academia Española agradece su colaboración a la Colombiana, la Mejicana y la Venezolana". La inclusión de esta marca es una de las cuestiones más características de esta edición, ya que, como ha investigado recientemente Clavería (en prensa), supone el uso de una marca que no se emplea, aunque con una ligera modificación, hasta la edición de 1884 ( $p r$. Cuba). Esto, según la hipótesis de esta investigadora, como se comentará en próximos epígrafes, parece estar relacionado con alguna de las fuentes de información empleadas durante la preparación de esta edición.

Existen también en esta edición otros cambios relacionados con el uso de las abreviaturas de marcación diatópica. Clavería (2001: 390) señala, por ejemplo, la eliminación de la marca prov. 'provincialismo' — que se había introducido en la edición anterior (1832) - en la segunda acepción de la voz buzón. Por ello, en futuras investigaciones sobre la microestructura de esta edición cabría plantearse el análisis detallado de las marcas diatópicas.

\section{ADICIONES: VOCES Y ACEPCIONES NUEVAS}

El análisis comparativo de la nomenclatura de la octava edición respecto a la anterior refleja, por un lado, que se trata de una edición en la que se trabajó con mucha celeridad, lo que generó erratas y errores de diverso tipo (p. e. algunas de las nuevas incorporaciones se introducen con idéntica definición y lematización en el Diccionario y en el Suplemento, tal y como había advertido Salvá (Álavarez de Miranda 2003: 105): contrapuntarse, crepuscular, cuellicorto, etc.); y, por otro lado, que la selección de voces que se incorporan responde a la necesidad constante de completar, actualizar y perfeccionar la obra (Rodríguez Barcia 2013).

En este apartado se va a llevar a cabo un estudio general de los nuevos lemas y nuevas acepciones del DRAE 1837 desde diferentes perspectivas lingüísticas con el fin de caracterizar el aumento del lemario en relación con su contexto histórico. El análisis parte de un corpus de 345 formas léxicas que se corresponden con 267 nuevos lemas ${ }^{4}$ y 65 nuevas acepciones cuya mayoría se hallan en el Suplemento, como puede apreciarse en los datos de la tabla 2:

\begin{tabular}{|c|c|c|c|}
\cline { 2 - 4 } \multicolumn{1}{c|}{} & Nuevos lemas & Nuevas formas & Nuevas acepciones \\
\hline Diccionario & 85 & 93 & 13 \\
\hline Suplemento & 182 & 187 & 52 \\
\hline Total & 267 & $280^{5}$ & 65 \\
\hline
\end{tabular}

Tabla 2. Nuevos lemas y acepciones en el DRAE 1837.

4 La diferencia numérica entre lema y forma está relacionada con los lemas múltiples. Se trata de casos que contienen más de una forma en un solo lema (p. e. bambú o bambuc $S$ constituye un nuevo lema y dos nuevas formas; otros casos similares son: brécol, brecolera $S$; cachamarin o cachemarin $S$; dragoman o drogman $S$; violoncelo o violonchelo, etc.). Asimismo, los diminutivos (avellanita, cestita, cestito, coplita, etc.) constituyen también nuevas formas pero no son nuevos lemas, porque se añaden a un lema ya existente en la edición anterior (p. e. cestita se añade a cestica, lla (1832) y el lema pasa a ser cestica, lla, ta).

5 En este recuento, no se incluyen las voces que cambian de forma (chisgarabis (1837) sustituye a chisgaravis (1832); infraganti sustituye a infragante (1832); intercolumnio (1837) sustituye a intercolunio (1832); sudsudues- 
La metodología empleada en este estudio se divide en dos fases: por un lado, a partir de la búsqueda y contraste de los datos del NTLLE se han obtenido los nuevos lemas y nuevas acepciones $\mathrm{y}$, por otro lado, se han clasificado y estudiado desde diferentes puntos de vista $(\S 4.1$ y $\S 4.2)$.

Los lemas nuevos que se recogen en la primera columna se han obtenido a partir del vaciado de la base de datos del proyecto "Historia interna del Diccionario de la lengua castellana de la Real Academia Española en el siglo XIX (1817-1852)” (FFI2014-51904-P) que se halla a disposición de cualquier usuario en la página web del mismo ${ }^{6}$.

Las nuevas acepciones que se recogen en la tabla 3, en cambio, se han obtenido, por un lado, a partir del análisis de las voces del Suplemento que no se correspondían con nuevas entradas y, por otro lado, a partir del cotejo de diferentes páginas al azar de 15 letras. Estos casos, aunque son muy pocos (solo 13 voces), permiten ayudar a completar la descripción de las tendencias que se advierten en esta edición y que deberían poder servir para abrir nuevas vías de investigación sobre esta, puesto que reflejan cuestiones interesantes en lo que respecta al origen y al ámbito semántico de las acepciones incorporadas.

\begin{tabular}{|c|c|}
\hline Diccionario & 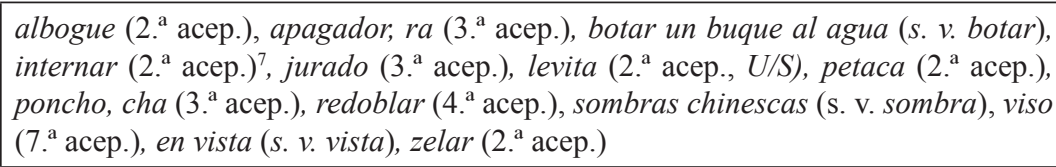 \\
\hline Suplemento & $\begin{array}{l}\text { adelantar, agá, apóstol (el), apoteosis, archimandrita, aristoloquia, aritmético, } \\
\text { astrágalo, baharí, bañar (el sol o el aire), beatificar, bergamoto, bola (ruede la), } \\
\text { borrasquero, ra, cabeza de lobo (ser o hacer), cabriolé, cañas (correr), capona, } \\
\text { carga (volver a), catastro, china, cierto, ta, clisar, desroblar, destructor, do, dueña, } \\
\text { efectivo (en), errada, extrañeza, faunos, figurar, flaco, fresco, ca (estar o quedar), } \\
\text { geodesia, globo (en), helenista, imperar, imperial, jalear, juno, lanzas (correr), } \\
\text { levita (U/S), maestro, martelo, matarife, matrimonio, otri, peón, rayar (el sol), sopa } \\
\text { boba (estar a la), timiama }\end{array}$ \\
\hline
\end{tabular}

Tabla 3. Acepciones nuevas en el DRAE 1837 que se han examinado.

En el recuento de las nuevas formas existen voces que son variantes ortográficas (villa $4 .^{\text {a }}$ acep. (1832) > billa $1 .^{\mathrm{a}}$ acep. (1837); villar (1832) > billar (1837)) o formales (conmensal $(1832)>$ conmensal y comensal $(1837)$; oréade (DRAE 1832) > oréada y oréade (DRAE 1837) mirabolano (1832) > mirabolano y mirobálano (1837)) de una voz ya presente en el lemario. Asimismo, existen 7 casos de primeras documentaciones que se pueden encontrar tanto en el interior del Diccionario como en el Suplemento sin

te (1837) sustituye a sudsuduoeste (1832)) ya que, aunque la búsqueda en el NTLLE las ofrezca como nuevas documentaciones, constituyen modificaciones gráficas o formales de voces ya documentadas en ediciones y las sustituyen en el lemario.

6 La página web del proyecto es http://draesxix.wixsite.com.

7 La incorporación de la segunda acepción parece estar relacionada con la corrección de la primera acepción que se recogía en la edición precedente. Contrástense las definiciones de las dos ediciones:

"INTERNAR. a. Penetrar ó entrar muy adentro ó tierra adentro. Se usa tambien como recíproco. \| r. met. Introducirse ó insinuarse en los secretos y amistad de alguno, ó profundizar alguna materia" (DRAE 1832).

"INTERNAR. a. Conducir una cosa tierra adentro. Úsase como recíproco tratándose de personas. || n. Penetrar. || r. met. Introducirse ó insinuarse en los secretos y amistad de alguno, ó profundizar alguna materia" (DRAE 1837). 
modificación alguna. Se trata de voces pertenecientes a las letras C y D (contrapuntarse, crepuscular, crisálida, cuellicorto, ta, depresivo, va, desconceptuar y dey) que se añaden en el cuerpo de la obra de la octava edición y vuelven, seguramente a causa de la premura con la que se preparó el texto, a incluirse en el Suplemento sin ningún cambio. A esto se refiere Vicente Salvá en las "Advertencias" en las que explica las mejoras que introduce en su versión del Diccionario de la lengua castellana por la Academia Española de 1838 publicado en París y que Álvarez de Miranda (2003: 105) califica como "un despiste académico". A lo largo de esta investigación se hará referencia a estos casos con la marca $U / S$, para indicar que se incluyen con igual forma y contenido en el cuerpo de la obra y en el suplemento que lo acompaña.

Son similares a estos casos los de otro grupo reducido de voces que se agregan también en los dos lugares de la obra como primeras documentaciones en la historia de la lexicografía académica y que pertenecen, en su mayoría, a las mismas letras que los anteriores pero que presentan algún tipo de modificación en el Suplemento, con la voluntad de corregir una definición (collonada, continental, contraalmirante, curiosear, desorganizar, levita), ampliar el número de acepciones (concertante), completar una definición (cólera morbo, constitucional, correccional, levita), añadir la equivalencia latina (collon, na, collonería), modificar información gramatical (colorante) o cambiar la lematización (cólera morbo, crapuloso, sa, imitativo, va):

\begin{tabular}{|c|c|}
\hline$D R A E 1837$ & DRAE 1837 Suplemento \\
\hline CHANADA. f. Superchería, incongruencia. & CHANADA. f. Truhanada, chasco. \\
\hline $\begin{array}{l}\text { CÓLERA-MORBO. m. Enfermedad conocida, } \\
\text { cuyo nombre se aplicó por la semejanza de sus } \\
\text { síntomas y efectos á la epidemica procedente de } \\
\text { Asia, que ha cundido por toda Europa en estos } \\
\text { últimos tiempos. }\end{array}$ & $\begin{array}{l}\text { CÓLERA MORBO. m. Med. Enfermedad aguda } \\
\text { cuyos síntomas son vómitos, cámaras frecuentes, } \\
\text { calambres, calentura, postracion de fuerzas y } \\
\text { frio en las extremidades [...]. \| ASIÁtico. El que } \\
\text { ademas de los síntomas anteriores se distingue por } \\
\text { su caracter epidemico, calor interno y frio externo } \\
\text { en sumo grado, ojeras moradas, hundimiento de } \\
\text { ojos, manchas azules por el cuerpo, y alteracion } \\
\text { extraordinaria de las facciones [...]. }\end{array}$ \\
\hline COLLON, NA. adj. Cobarde. & COLLON, NA. adj. Cobarde. Ignavus. \\
\hline COLLONADA. f. Propiedad del cobarde. & COLLONADA. f. Accion propia de cobardes. \\
\hline COLLONERÍA. f. Cobardía. & COLLONERÍA. f. Cobardía. Ignavia. \\
\hline COLORANTE. p. a. Lo que da color. & COLORANTE. adj. Lo que da color ó tinte. \\
\hline $\begin{array}{l}\text { COMENSAL. m. Compañero en la mesa. } \\
\text { Convictor; mensa socius. }\end{array}$ & $\begin{array}{l}\text { COMENSAL. m. Conmensal. Convictor, mensa } \\
\text { socius. }\end{array}$ \\
\hline $\begin{array}{l}\text { CONCERTANTE. p. a. de concertar. Lo que } \\
\text { concierta. }\end{array}$ & $\begin{array}{l}\text { CONCERTANTE. adj. Mús. que se aplica á la } \\
\text { pieza compuesta de dos ó mas voces entre las } \\
\text { cuales se distribuye el canto. }\end{array}$ \\
\hline $\begin{array}{l}\text { CONTINENTAL. adj. Lo que pertenece á los } \\
\text { paises del continente. }\end{array}$ & $\begin{array}{l}\text { CONTINENTAL. adj. Lo que pertenece al } \\
\text { continente ó tierra firme. }\end{array}$ \\
\hline
\end{tabular}




\begin{tabular}{|c|c|}
\hline$D R A E 1837$ & DRAE 1837 Suplemento \\
\hline $\begin{array}{l}\text { CONSTITUCIONAL. adj. Lo perteneciente á la } \\
\text { constitucion. }\end{array}$ & $\begin{array}{l}\text { CONSTITUCIONAL. adj. Lo perteneciente á la } \\
\text { constitucion de un estado. }\end{array}$ \\
\hline $\begin{array}{l}\text { CONTRAALMIRANTE. m. Oficial de la marina } \\
\text { de algunas naciones, que equivale en la nuestra á } \\
\text { jefe de escuadra. }\end{array}$ & $\begin{array}{l}\text { CONTRAALMIRANTE. m. En la marina } \\
\text { inglesa y de otras naciones equivalente á jefe de } \\
\text { escuadra. }\end{array}$ \\
\hline $\begin{array}{l}\text { CORRECCIONAL. adj. Lo que conduce á la } \\
\text { correccion. }\end{array}$ & $\begin{array}{l}\text { CORRECCIONAL. adj. Lo que conduce ó se } \\
\text { dirige á la correccion. }\end{array}$ \\
\hline $\begin{array}{l}\text { CURIOSEAR. v. n. Ocuparse en averiguar lo que } \\
\text { otros hacen ó dicen. }\end{array}$ & $\begin{array}{l}\text { CURIOSEAR. m. Meterse á averiguar lo que es } \\
\text { ajeno de la incumbencia propia. }\end{array}$ \\
\hline CRAPULOSO. adj. Dado á la crápula. & CRAPULOSO, SA. adj. Dado á la crápula. \\
\hline DESORGANIZAR. a. Desarreglar, desordenar. & $\begin{array}{l}\text { DESORGANIZAR. a. Desordenar, descomponer } \\
\text { en sumo grado. }\end{array}$ \\
\hline $\begin{array}{l}\text { IMITATIVO. adj. Lo perteneciente á la imitacion; } \\
\text { como artes imitativas; armonia imitativa. }\end{array}$ & $\begin{array}{l}\text { IMITATIVO, VA. adj. Lo que pertenece á } \\
\text { la imitacion; como artes imitativas; armonia } \\
\text { imitativa. }\end{array}$ \\
\hline $\begin{array}{l}\text { LEVITA. m. El israelita de la tribu de Leví } \\
\text { dedicado al servicio del templo. Levita. \| } \\
\text { DIÁcono. || f. Traje moderno de hombre que se } \\
\text { diferencia de la casaca en que los faldones son de } \\
\text { tal amplitud que se cruzan por delante. }\end{array}$ & $\begin{array}{l}\text { LEVITA. f. Especie de casaca de faldones anchos } \\
\text { y que cruzan por delante. }\end{array}$ \\
\hline
\end{tabular}

Tabla 4. Primeras documentaciones del DRAE 1837 y modificadas en el Suplemento a esta edición.

Se trata, según anotó Salvá en el prólogo de su edición de 1838, de 15 casos (Álvarez de Miranda 2003: 105), a los que puede añadirse alguno más (imitativo, va). Cabe señalar que diversos de estos cambios recogidos en la tabla 4 que se incorporan en el Suplemento se pierden en la historia del Diccionario, pues en la edición siguiente no se incorporan o no se tienen en cuenta, como es el caso de chanada, cuya segunda acepción propuesta no se incluye en la 9. a edición (1843), o levita (2. a acep.) y contraalmirante, voces sobre las que la corrección de la definición que se había propuesto en el Suplemento de 1837 no se tiene en cuenta para las siguientes ediciones y se mantiene la que se había incluido en el cuerpo del Diccionario de la octava edición. Se trata de modificaciones que, en su mayoría, se asocian a la definición. De estos datos se deduce que en las primeras letras se trabajó bastante, pues la mayoría de estas cuestiones corresponden a las primeras (de los 17 ejemplos de la tabla 4, 13 pertenecen a la letra C), por ello, quizá, se podría pensar que las labores de corrección y aumento fueron mucho más precisas y detalladas en estas que en las siguientes.

Asimismo, cabe señalar que algunas de las incorporaciones de esta edición que se contemplan como nuevas entradas constituyen la recuperación de un lema que ya existió en la nomenclatura del diccionario académico pero que fue suprimido en alguna de las ediciones de la primera mitad del siglo XIX. Es el caso, por ejemplo, de las voces otri 'lo mismo que otro' y reflectar 'reflejar', que desaparecen en la edición de 1822 hasta que vuelven a incorporarse en la octava edición. Algo similar sucede con timiama, una voz 
que se recoge por última vez en 1803 con el significado de 'perfume con un olor suavísimo’ y en la edición de 1837 vuelve a aparecer en el lemario pero con una definición más completa: 'entre los judíos confección olorosa reservada al culto divino, castigándose con pena capital al que la empleaba en usos profano'.

\subsection{Estudio gramatical y morfológico}

Un análisis detallado de las voces revela que el grueso del aumento de formas de esta edición lo conforman sustantivos y adjetivos referentes a diversos campos semánticos (vid. $\S 4.2$ ). Se trata del $90 \%$ del total del corpus, mientras que el $10 \%$ restante lo constituyen verbos y frases proverbiales en su mayoría. En cambio, en las nuevas acepciones, aunque el aumento de sustantivos y adjetivos también es más elevado que el de otras categorías (supone un $63 \%$ del total de nuevas acepciones), destaca una gran cantidad de frases proverbiales (cfr. tabla 3), tal y como ilustra la tabla 5:

\begin{tabular}{|c|c|c|c|c|}
\hline Clase de palabra & $\begin{array}{l}\text { Número nuevas de } \\
\text { formas }\end{array}$ & $\%$ & $\begin{array}{c}\text { Número de nuevas } \\
\text { acepciones }\end{array}$ & $\%$ \\
\hline Sustantivos & 185 & \multirow{2}{*}{$90 \%$} & 35 & \multirow{2}{*}{$63 \%$} \\
\hline Adjetivos & 71 & & 6 & \\
\hline Verbo & 22 & \multirow{2}{*}{$10 \%$} & 11 & \multirow{2}{*}{$37 \%$} \\
\hline Otros & 2 & & 13 (frases) & \\
\hline Total & 280 & & 65 & \\
\hline
\end{tabular}

Tabla 5. Voces y acepciones incorporadas según su categoría gramatical.

Desde un punto de vista morfológico puede observarse que las voces o acepciones incorporadas son derivados de alguna forma simple documentada con anterioridad en el Diccionario, lo que podría ser un reflejo de la voluntad de completar familias léxicas, ya que casi el 50\% de este grupo de voces son formas derivadas (son testimoniales los compuestos léxicos entre las formas incorporadas (cargareme, $S^{8}$; cuellicorto, ta; escampavía $S$ ). Sirvan de ejemplo, algunas voces formadas con los sufijos -ada (andaluzada $S$; collonada U/S; judiada $S$; testarada; etc.), -ado (apazcuado, da; episcopado $S$; incomunicado, da $S$; acaramelado, da $S$; amazacotado, da $S$; etc.), -al (cerebral $S$; colonial; constitucional U/S; correccional U/S; imperial $S$; etc.), -ero (borrasquero, ra S; guerrillero, ra S; rutinero, ra $S$; yesquero, etc.), -ble (calcinable, $S$; calculable, $S$; disimulable $S$; incalculable $S$, etc.), -ismo (empirismo $S$; galvanismo $S$, etc.), -ista (bautista $S$; ergotista $S$; folletista $S$, etc.), -miento (comportamiento; embrutecimiento $S$; ludimiento, $S$; rozamiento), -oso, sa (crapuloso, sa; cuarzoso, sa; escirroso, sa $S$; gaseoso, sa $S$; hiposo, sa $S$; veleidoso, $s a$ ). Se advierte que la mayoría de voces derivadas incorporadas son sufijadas, aunque existen también ejemplos de grupos de voces prefijadas como muestran los casos formados con contra- (contralmirante, contrabarrera, contrapuntarse), in- (incalculable $S$; inconcebible $S$; incomunicación $S$; incorrección $S$; insubordinación $S$, etc.) o des- (desconceptuar; desempolvar; desorganizar; desaceitar).

8 Las voces incorporadas en el Suplemento aparecen seguidas de la letra $S$. 
Existen también adiciones de formas diminutivas (amiguito, ta $S$; avellanita; calveta; cestita; cestito; coplita y dueto) o aumentativas (amigazo, za; inocenton, na, S; tacazo) de algunas voces ya incluidas en el Diccionario. Sobre los diminutivos debe tenerse en cuenta que la mayoría de los que entran completan la serie de dos variantes que formaban ya parte del lemario en la edición anterior (7. ${ }^{a}$ ed., 1832), el único caso excepcional es el de amiguito, ta, pues entra como lema nuevo en el Suplemento sin tenerse en cuenta que existe ya documentada la forma amiguillo, lla. Este caso, como puede verse en la tabla 6, se aleja del resto que se ha analizado y podría mostrar, de nuevo, la precipitación con la que se trabajó en la incorporación de nuevas formas:

\begin{tabular}{|l|l|}
\hline \multicolumn{1}{|c|}{ DRAE 1832 } & \multicolumn{1}{c|}{ DRAE $\mathbf{1 8 3 7}$} \\
\hline amiguillo, lla & amiguito, ta $(S)^{9}$ \\
\hline cestica, lla & cestica, lla, ta \\
\hline cestico, llo & cestico, llo, to \\
\hline coplica, lla & coplica, lla, ta \\
\hline nuevecito, llo & nuevecico, llo, to \\
\hline
\end{tabular}

Tabla 6. Diminutivos de nueva incorporación en el DRAE 1837.

Estos ejemplos manifiestan la voluntad de seguir el criterio "implícito" de homogeneización y organización alfabética de las variantes diminutivas (Prat 2018: 104) que se había establecido a partir de la publicación de la GRAE (1796) y reflejan también la necesidad de ofrecer una obra más completa con las formas diminutivas más frecuentes, algo que, más adelante, en la penúltima edición del siglo XIX, se desechará por considerarse innecesaria su aparición en la microestructura (Garriga 2001).

Esta homogeneización en los diminutivos que intenta recoger varias formas derivadas relacionadas con diferentes morfemas pero relativas a un mismo significado parece que trata de aplicarse de modo similar en otros casos, pues se incluyen bajo la misma entrada derivados de una misma familia léxica con distinto valor semántico. En esta edición se han encontrado dos casos de este tipo: brécol, lera $(S)$ y galvánico, ca, nismo. Se trata de adiciones especiales en las que destaca la ausencia de la definición de alguna de las formas derivadas o de todas ellas.

Brécol, lera $(S)$ remite a bróculi 'variedad de la col común que se distingue principalmente en que sus hojas no se apiñan, son de un color más oscuro y están cortadas en tiras' (DRAE 1837), sin embargo, la remisión solo puede identificarse con la primera forma (brécol), ya que la segunda (brecolera) no presenta definición hasta dos ediciones posteriores (DRAE 1852), cuando se identifica como una 'especie de bróculi, que echa pellas a semejanza de la coliflor'.

El segundo caso (galvánico, ca, nismo) es también interesante porque se incorpora como lema múltiple pero no se incluye ningún tipo de información gramatical ni remisión ni definición alguna sobre estas voces que permita redirigir al lector a un significado, por lo que se trata de otro error. Si se realiza una búsqueda en el NTLLE se advierte que el Dicciona-

9 Se conserva, además, la forma amiguillo, lla. 
rio recoge la palabra galbanismo desde la edición de 1822 (Med. 'la propiedad de excitar movimientos espasmódicos en los nervios y músculos') y que galvánico, ca son primera documentación desde 1837. Esto refleja, de nuevo, la celeridad con la que se trabajó para completar las familias de palabras incorporadas en el Diccionario, pues se incluyen mediante lematización múltiple cuando, en realidad, por tratarse de voces con distinta definición deberían lematizarse como entradas distintas.

\subsection{Estudio semántico, etimológico y documental}

Desde un punto de vista semántico, son diversas las tendencias que se advierten en el conjunto de incorporaciones de la octava edición del Diccionario y a partir del estudio de estas podrían determinarse los criterios de selección de los términos y definiciones incorporados. Un examen general permite comprobar la gran variedad de áreas semánticas a las que se corresponden las nuevas adiciones, tal y como había advertido Clavería (2016: 112) en el análisis del Suplemento (alimentos, animales, anatomía, arquitectura, astronomía, botánica, comercio, geografía, geometría, indumentaria, juegos, leyes, medicina, medidas, metalurgia, milicia, mitología, música, náutica, objeto, oficios, persona, plantas, poesía, política, química, religión, teatro, transporte). Se trata tanto de léxico común como de léxico de especialidad científico-técnico y humanístico-social, aunque algunas voces se hallen a medio camino entre el uso general y el especializado (es el caso del vocabulario del comercio y la economía o la música). Por ello, y partiendo de uno de los pocos aspectos que el Prólogo menciona sobre el tipo de vocabulario de nueva admisión (el léxico común), en los siguientes apartados se presenta un estudio basado en una clasificación en dos grandes grupos: voces del léxico común o general (\$4.2.1.) y voces del léxico de especialidad (\$4.2.2.).

A pesar de que se trata de una división arriesgada si se tiene en cuenta que, como afirma Pérez Pascual (2012: 207), "no está claro que se pueda establecer una frontera entre el léxico general (compuesto por palabras) y el especializado (compuesto por términos); y ello sucede debido a la transformación continua de palabras en términos y de términos en palabras", la presentación del estudio de los datos en estos dos grandes bloques ha parecido la más acertada para poder manejar las más de trescientas palabras que conforman el corpus y así poder obtener una visión general de los rasgos que comparten los vocablos y acepciones que fueron elegidos para formar parte de la nomenclatura de la octava edición.

\subsubsection{El léxico común}

En este grupo se compila el $60 \%$ de las voces incluidas en el corpus de esta investigación, lo que refleja esa preocupación por completar el Diccionario con voces de uso general a la que los académicos aluden en el Prólogo (\$2). El análisis del léxico común resulta más complejo que el del léxico de especialidad, puesto que los ámbitos semánticos son más amplios y es difícil acotar el área en la que se emplea la voz a partir solo de su significado. No obstante, si se realiza una clasificación general de las voces, se observa que existen determinadas áreas sobre las que ha habido más incorporaciones que otras y que diversas de ellas son préstamos referidos a objetos y otras realidades llegados de otras partes del mundo (vid. tabla 7). 
Debido a la gran cantidad de términos que pertenecen al léxico común y a la dificultad que supone llevar a cabo un análisis completo de todas las voces de este grupo, se han seleccionado para el análisis de este apartado las voces que se refieren a una realidad física vinculada a un ámbito específico o que mantienen relación con alguna de las diez áreas semánticas que se han distinguido a continuación:

\begin{tabular}{|c|c|}
\hline Ámbito semántico & Voces y acepciones \\
\hline Alimentos (1) & cuscurro \\
\hline Colores (5) & cerusa $(S)$, colorante $(U / S)$, colorete $(\mathrm{S})$, indigo, negron \\
\hline Indumentaria y tejidos (8) & $\begin{array}{l}\text { calcetin }(S), \text { cúbica }(S), \text { desaceitar, figurin }(S), \text { frac }(S) \text {, levita }(U / S \\
\text { acep. })^{10}, \text { poncho, cha (acep.), viso (acep.) }\end{array}$ \\
\hline Juegos (5) & chambon, chambonada, encarte $(S)$, entable $(S)$, errada $(S$, acep.) \\
\hline Oficios (7) & $\begin{array}{l}\text { anteojero, canillaire, folletista }(S) \text {, jalmero }(S) \text {, helenista }(S \text {, } \\
\text { acep.), matarife }\left(S \text {, acep.), yesquero }\left(2 .^{\text {a }} \text { acep. }\right)\right.\end{array}$ \\
\hline Partes del cuerpo (1) & curcusilla $^{11}$ \\
\hline $\begin{array}{l}\text { Países, pueblos, su cultura y } \\
\text { costumbres (12) }\end{array}$ & $\begin{array}{l}\text { caimacan }(S), \text { calmuco, ca }(S), \text { cosaco, ca }(S) \text {, guanches }(S \text {, acep. }), \\
\text { dey }(U / S) \text {, esquimal, genovesado }(S) \text {, guillotina }(S), \text { guillotinar } \\
(S) \text {, hospodar }(S) \text {, hotentote, ta }(S), \text { naboria }(S)\end{array}$ \\
\hline Tabaco (3) & petaca (acep.), fumador, ra $(S)$, yesquero (1. acep.) \\
\hline Transportes (4) & cabriolé $(S$, acep.), carretela $(S)$, faeton $(S)$, volanta \\
\hline Otros (5) & antojera $(S)$, buró $(S)$, calavernario, catacumbas $(S)$, tija \\
\hline
\end{tabular}

Tabla 7. Algunas incorporaciones en el $D R A E 1837$ del léxico común.

El resto de voces y acepciones que no se pueden incluir en esta clasificación se corresponden con realidades más abstractas, como acciones comunes y cotidianas (adelantar $S$, acep.; acollonar; cominear; curiosear U/S; desempolvar; desorganizar U/S; internar acep.; improvisar; jalear $S$, acep.; zelar, etc.); características o rasgos de personas (crapuloso, sa $U / S$; collon, na U/S; cuellicorto, ta U/S; encomiador, ra; estupefacto, ta $S$; gandul S; gatallon, na $S$; hiposo, sa $S$; mentecatez) o de otras realidades (acaramelado, da $S$; amazacotado, da $S$; atentatorio, ria $S$; calcinable $S$; coercitivo, va $S$; correccional $U / S$; disimulable $S$; disponible $S$; evasivo, va $S$; giratorio, ria $S$; imitativo, va $U / S$; incalculable $S$; incoherente $S$; incomunicado, da, $S$; insignificante, $S$; insonoro, ra $S$; etc.) y conceptos abstractos (chanada U/S; charada; cohesion $S$; collonada U/S; collonería $S$; comportamiento $S$; culpabilidad; cuarterola $S$; equipo; fetidez; filipica; imprevision U/S; incoherencia $S$; incorreccion $S$; insalubridad; jaleo $S$; judiada; subterfugio; tacazo; testarada, etc.).

10 La abreviatura acep. indica que se trata de la incorporación de un significado nuevo a un lema ya existente (vid. tabla 2) en la edición anterior (1832). Asimismo, en el caso de que haya más de una acepción en el nuevo lema incorporado también se indica. Véase el caso de yesquero, que es un nuevo lema con dos acepciones y cada una de ellas corresponde con uno de los ámbitos semánticos en los que se ha distribuido el corpus del léxico común. 11 Otra muestra de la precipitación de los trabajos de corrección y aumento es el hecho de que esta voz se introduzca antes de cúrcuma, pues alfabéticamente debería situarse justo después de esta. Según la revisión de Salvá (Álvarez de Miranda 2003: 106), son hasta 78 las voces que quebrantan el orden alfabético en la octava edición. 
De este grupo destacan, por ejemplo, el adjetivo collon, na $(U / S)$ con el significado de 'cobarde' —que, según el DECH (s. v.), llega al español por conducto del francés coïon o couillon 'hombre flojo y sin energía', pero su origen es el italiano coglione 'tonto, majadero'- y los tres derivados que se relacionan con él: acollonar 'acobardar', collonada $(U / S)$ 'propiedad del cobarde' $(U)$ y 'acción propia de cobardes' $(S)$ y collonería $(U / S)$ 'cobardía', cuyo origen cabría estudiar con más detalle en otro trabajo. Asimismo, sobresalen otros préstamos del italiano (martelo 'galanteo, enamoramiento') o del francés (charada 'acertijo, enigma quisicosa', equipo $S$ 'acción y efecto de equipar', según datos del $D E C H$ ).

A continuación se analizan de forma más detallada algunas de las voces de la tabla $7^{12}$ con el fin de caracterizar el nuevo léxico seleccionado para la octava edición.

\subsubsection{Indumentaria y tejidos}

En el grupo de indumentaria y tejidos se incluyen voces relativas a prendas de ropa de diverso tipo, algunas de las cuales procedían de otras culturas y eran el reflejo de la influencia del mundo anglosajón y francés en la moda de la época, como es el caso de las dos prendas de abrigo que se incluyen en el cuerpo del Diccionario y en el Suplemento (frac $S$ y levita U/S). Se trata de un ámbito semántico que, de acuerdo con Álvarez de Miranda (2004: 1037), "sería deseable conocer históricamente [... porque] prácticamente nada ha sido hecho en este terreno por los filólogos", con excepción del trabajo de Lapesa (1989) sobre la vida social y la indumentaria de la época romántica en la que se determina la abundancia de los galicismos, lo que se puede comprobar en las páginas de la octava edición del Diccionario. El frac se define como una 'especie de casaca con solapas que cruzan sobre el pecho' y, según el $D E C H(s . v$.), este sustantivo llega al español a través del francés y este idioma parece que lo habría tomado del inglés ("fr. frac íd., tomado probablemente del ingl. frock 'hábito de fraile', 'bata de mujer o de niño', 'frac', préstamo a su vez del fr. froc 'hábito de fraile', y éste del fráncico *HROKK 'chaqueta"') y, según datos del CORDE (s. v. frac), la primera documentación se halla en un texto de finales del siglo XVIII (Loa para la comedia "La vida es sueño" [Loas], 1772-1773) de Vicente García de la Huerta en el que, además de frac, se documentan otros galicismos relativos a la moda (cabriolé, sortú). De igual modo, la incorporación de la acepción levita con el significado de 'especie de casaca con faldones más anchos y que cruzan por delante' es el reflejo de la gran influencia de la cultura francesa en las costumbres de la España de la primera mitad del siglo XIX. Es voz también tomada del francés, ya que procede del sustantivo lévite que es "nombre aplicado a esta prenda por parecerse a la que llevaban los levitas en las representaciones teatrales" (DECH, s. v.) y se halla documentada por primera vez, según las ocurrencias del CORDE, en el Epistolario de Leandro Fernández de Moratín, concretamente en las Cartas de 1815. Este autor volverá a emplear el término en otro texto epistolar relacionándolo con algunas otras prendas cuyos nombres también son de origen francés:

Las ropas floxas dan lugar al estudio de los pliegues; y una casaca o frac o levita ceñida al cuerpo no puede hacer tan buen efecto como una vestidura ancha, capaz de plegaturas

12 Con el fin de evitar la repetición de información innecesaria, en el comentario de los datos procedentes de la tabla 7 no se incluyen las abreviaturas que en la tabla se han usado para situar las voces en el Suplemento y para indicar que se trata de una acepción nueva. 
y dobleces, de que resulta la variedad de líneas y la oposición de luces y sombras, que tanto hermosean en una pintura (Leandro Fernández de Moratín, Cartas de 1817, p. 361, Epistolario).

A juzgar por los datos del corpus es evidente que la Corporación sigue manteniendo el criterio de autoridad en la inclusión de estas voces en el Diccionario, puesto que desde su primera documentación en 1817 hasta la publicación de la 8. ${ }^{a}$ edición en 1837, se documentan 30 ocurrencias de la voz levita en obras de autores tan relevantes e influyentes de la época como José Joaquín Fernández de Lizardi, Tomás José González Carvajal, Mariano José de Larra y Ramón de Mesonero Romanos, entre otros.

Entre las otras palabras de este grupo son interesantes las adiciones de la voz calcetín y una acepción referida a la ropa en la voz viso 'el forro de color, o el traje interior que suelen usar las mujeres debajo del vestido de tela clara, para que por ella se trasparente', ya que suponen la incorporación de significados comunes en el vocabulario de la indumentaria que han pervivido hasta nuestros días en el español europeo. El calcetín definido como la 'calceta o media que solo llega a la pantorrilla' se incorpora como nuevo lema, voz que mantiene relación con calceta, derivado de calza (DECH, s. v. calza). Este tipo de creaciones patrimoniales no son extrañas al léxico de la moda, ya que, según Štrbáková (2007: 334), el diminutivo -ín es productivo en la creación de voces referidas a la indumentaria (batín, camisolín, chalina, percalina), incluso añadiéndose a préstamos procedentes de otras lenguas (levitín). Según el $C D H$, la primera documentación corresponde a una poesía de 1828 de Manuel Bretón de los Herreros (Poesías, Madrid, Imprenta Miguel Ginesta), en cambio, el CORDE la documenta por primera vez casi sesenta años más tarde en un texto de Benito Pérez Galdós de 1874 (Juan Martín el empecinado). Bretón de los Herreros aparece por primera vez mencionado entre los Académicos Honorarios ${ }^{13}$ como "bibliotecario segundo de la nacional" en la edición de 1837. Por ello, es probable que la participación de Bretón de los Herreros en las obras académicas no empiece, como se ha supuesto anteriormente (Sánchez Salas 1999), en la edición de 1843, sino que ya lo hiciera de forma más o menos directa en la de 1837:

[... Bretón de los Herreros trabajó] intensamente en la publicación de la novena (1843), décima (1852) y undécima (1869), asociadas cada una de ellas a un escalafón en su carrera dentro de la Academia: el ascenso a plaza numeraria (14/V/1840, sustituyendo al Conde Montijo), la obtención del cargo de secretario perpetuo (20/I/1853, sustituyendo al fallecido Juan Nicasio Gallego, del cual fue amigo y hasta albacea testamentario) (Sánchez Salas 1999: 366).

Sin embargo, cabría revisar con detalle la documentación de algunas otras voces nuevas de la octava edición para confirmar su influencia. Entre otros casos, parece singular la inclusión de una acepción referida a la indumentaria en la entrada poncho, cha, pues el significado que se incorpora tiene origen en una prenda de vestir usada en América que se define como 'sayo sin mangas que se pone por la cabeza a modo de casulla', un significado que, según el $D E C H$ (s. v.), no adquiere hasta el siglo XVIII. La procedencia de la voz no está clara (Mora 2007: 466-467), algunos autores (Garavaglia 2002, Ariza 2011) la asocian con el araucano (pontho),

13 En la novena edición ( $D R A E$ 1843) se incluye entre los académicos de número y se amplia y modifica la información sobre su persona: "secretario honorario de S. M. y bibliotecario primero cesante de la nacional de esta Corte". 
otros con el quichua (pinchu) o con el español (poncho o pocho, DECH s. v. y Morínigo 1955). Según Ariza (2011: 19), la voz es claramente de origen araucano y de incorporación tardía en el DRAE si se compara con otros términos —en total 170 indigenismos - que ya aparecen desde el Diccionario de autoridades (p. e. bejuco, iguana, piragua).

Estrechamente relacionada con este último término se encuentra la voz cúbica, que se incluye en el Suplemento y cuyo uso parece también de procedencia americana a juzgar por su documentación en el Diccionario de voces cubanas de Pichardo (1836) y definida en él como 'tela de lana de un tejido descubierto con que se hacen casacas, levitas y cosas semejantes'. Se documenta también, según el Fichero General de la Real Academia Española, en Obras en verso y prosa de José Somoza fechada en 1820 ("Porque el niño no tenía otro vestido que una levita abierta de cúbica que habría sido encarnada y desechada sin duda por otro chico de más edad", p. 138). Se trata de una obra que actualmente se encuentra en una compilación de obras del autor que publicó en 1842 (Poesías y obras en prosa), pero a juzgar por los datos del Fichero, la Corporación dispuso del poema en el que se encontraba esta voz antes de la publicación completa de la obra. En Hurtado (2006), quien dedica un estudio a la labor de José Somoza como traductor, se indica que, además de los trabajos sueltos aparecidos en el Semanario Pintoresco Español, preparó la edición de sus Obras poéticas entre 1832-1837, por lo tanto, tal vez es esta la recopilación con la que contaba la RAE para incluir más de una de las palabras de sus poemas en la octava edición del Diccionario. El $D E C H$ explica que ya a principios del siglo XIX se documenta en catalán la forma cúbica (cfr. $D C V B$ s. v.), por ello, quizá, podría suponerse un origen francés.

Además de las prendas de ropa, existen otras voces que parecen estar relacionadas con el ámbito de la confección y los tejidos: figurin es el 'dibujo o modelo pequeño para los vestidos y adornos de moda' y desaceitar es el único verbo relacionado con este campo semántico y que se emplea con el sentido de 'quitar el aceite a los tejidos y otras obras de lana'.

\subsubsection{Juegos}

En el ámbito de los juegos las incorporaciones se vinculan a los naipes (encarte), al billar (errada) y a las damas o ajedrez (entable), además de incluirse voces generales para describir a los jugadores y su destreza (chambon, chambonada). Según el DECH (s. v. chamba), chambón parece voz derivada del portugués antiguo chamba 'pierna', en el sentido de 'zancarrón', 'patán' y chambonada procede de ella. La discusión etimológica que se ofrece en este diccionario permite advertir, de nuevo, la relación del sustantivo con el español de América y también el vínculo de esta entrada con Manuel Bretón de los Herreros y la obra de Pichardo, según los datos del DECH (s. v. chamba):

Chambón 'el poco diestro o torpe en el juego', usado por Bretón de los Herreros (Pagés), ya está en Acad. 1843 (no 1817) y, con la equivalencia 'chapucero', en el dicc. de voces cubanas de Pichardo, 1836 (1875). Esta última ac. es la general en América, según explica Gagini: "se aplica sobre todo al obrero torpe, poco diestro en su oficio, y en general a la persona inhábil, desmañada"; así ocurre no sólo en Costa Rica, sino también, a juzgar por los derivados chambonear y chambonada, en la Arg., Chile, Perú, Méjico, Bolivia, Ecuador y Venezuela (Malaret), y también en Canarias y en Asturias ("el que en su oficio hace y remata mal las cosas": Rato). La ac. de chambón 'el que consigue algo por chiripa', se desarrolló más tarde y todavía no se halla en Acad. 1899. 
El $C D H$ recupera la primera documentación de esta voz con el significado de 'chapucero’ en 1816 en una obra mexicana de José Joaquín Fernández de Lizardi titulada El periquillo Sarniento y para el español europeo el corpus recupera una primera documentación en 1828, de nuevo, en Poesías de Bretón de los Herreros.

Los ejemplos de entable 'la acción de entablar, y la varia disposición de los juegos de damas, ajedrez, etc.' y encarte 'en el juego de naipes el orden casual en que las cartas quedan al fin de cada mano, y suele servir de guía a los jugadores para la siguiente' parecen estar vinculados formalmente.

En el ámbito del juego del billar, son diversas las novedades: errada, billar y billa. La acepción errada identifica 'en el juego del billar, cada golpe en que tirando el jugador no toca con su bola a la que debe herir'. Billar y billa son dos nuevas incorporaciones cuya adición parece estar relacionada con el cambio ortográfico que se anunciaba en el Prólogo. Estas dos voces cambian la $v$ por la $b$ en la octava edición. El origen del cambio parece que se halla en la aplicación la segunda regla establecida en el capítulo I de la Ortografía (1820: 9) que se basa en el principio de mantener la ortografía original en el caso de que exista dificultad en la relación entre pronunciación y escritura:

\section{II}

Todas las voces en que la pronunciación por sí sola no puede servir de gobierno, y el origen es conocido, se deberán escribir conforme á él habiendo uso común y constante de escribirlas de este modo; bien que se usará de los caractéres propios de nuestra lengua, que sean equivalentes en la pronunciación.

Entre las voces que se hallaban en esta situación debían estar billar 'juego' — cuyo origen es el francés billard - y billa 'lance del juego del billar', pues ambos sustantivos desde el Diccionario de autoridades hasta la séptima edición (1832) aparecían bajo villar y villa, respectivamente, y en esta edición cambian su ortografía y eso genera cambios en la nomenclatura y también en la definición de estos vocablos. En la tabla 8 se puede observar la corrección que se realiza en la segunda acepción de villar, que pasa a ser una entrada independiente después del cambio ortográfico de villar a billar, y la desvinculación de billa de villa:

\begin{tabular}{|c|l|}
\hline \multicolumn{1}{|c|}{ DRAE 1832 (s. v. villar, 2. ${ }^{\text {a }}$ acep.) } & DRAE 1837 (s. v. billar, 2. ${ }^{\text {a }}$ acep.) \\
\hline $\begin{array}{l}\text { Juego al modo de los trucos; pero la mesa no tiene } \\
\text { barra ni bolillo, y las tablillas son lisas con seis } \\
\text { troneras, cuatro a los extremos y dos en medio. }\end{array}$ & $\begin{array}{l}\text { Juego parecido al de los trucos pero la mesa no } \\
\text { tiene barras ni bolillo. Las troneras no son más } \\
\text { que seis, una en cada esquina, y dos en medio. }\end{array}$ \\
\hline DRAE 1832 (s. v. villa, . $^{\text {a }}$ acep.) & DRAE 1837 Suplemento (s. v. billa) \\
\hline $\begin{array}{l}\text { En el juego del villar la suerte de introducir } \\
\text { la bola propia o la contraria en alguna de las } \\
\text { torneras, que también se llaman villas. }\end{array}$ & $\begin{array}{l}\text { Lance en el juego de billar, que consiste en } \\
\text { que después de herir el jugador con su bola } \\
\text { a cualquiera de las otras, entre alguna en la } \\
\text { tronera. Si entra la bola del jugador, se llama } \\
\text { billa limpia; si entra alguna de las otras, billa } \\
\text { sucia o puerca. }\end{array}$ \\
\hline
\end{tabular}

Tabla 8. Villar-billar y villa-billa en el DRAE 1832 y 1837. 
Los cambios ortográficos de estas dos voces son solo una muestra de la reforma que se pretendió llevar a cabo. En materia de ortografía son muchos otros los cambios que se observan, especialmente en las definiciones, un aspecto al que Salvá dedica un espacio en la "Advertencia" de su edición de 1838 (Álvarez de Miranda 2003: 104) —especialmente para señalar las inconsistencias - y que sería interesante examinar en futuras investigaciones, pues parece que se consolidan, en esta edición, cambios importantes en este aspecto.

\subsubsection{Oficios}

Entre los nombres de oficios ${ }^{14}$, el grupo de incorporaciones es heterogéneo y el análisis de las voces que se incluyen en él sirve para constatar una de las tendencias más generalizadas de esta edición: la influencia de la lengua, la cultura y las costumbres de otros idiomas en la época y su reflejo en la lengua.

En anteojero 'el que hace, compone y vende anteojos', por ejemplo, palabra que no se documenta en los corpus consultados $(C O R D E, C D H)$, parece existir influencia francesa a juzgar por los datos de la primera documentación que hemos hallado en el Fichero General de la Real Academia Española. Esta palabra se recoge en la traducción española del libro Art du cartonnier del francés Jerôme de La Lande de 1762 que realizó Miguel Geronymo Suarez y Nuñez en 1776 y que se incluye al final de la traducción de una obra mayor, el Arte de hacer el papel segun se practica en Francia, y Holanda, en la China, $y$ en el Japon. El texto francés se refiere a los diferentes oficios en los que se usan las cajas de cartón ("les boites couvertes du vernis le plus précieux se font avec du carton; les Merciers, les Miroitiers, les Foureurs, les Papetiers, les Bourreliers, les Chapeliers, les Cordonniers en fon aussi beaucop d'usage", p. 2) y, en la versión española, M. G. Suárez traduce estas voces del siguiente modo: "las caxas cubiertas con el más precioso barniz, se hacen de cartón: los Mercaderes de Mercería, los del Papel, los Anteojeros, Sombreros, Estucheros, Guarnicioneros, Zapateros, y otros hacen de él bastante consumo" (M. G. Suárez 1776, p. 250). Según el texto original en francés, la palabra anteojero se propone como traducción del francés miroitiers. Una traducción que no parece adecuada partiendo del significado de esta voz en francés según el $T L F i(s . v$.): "personne qui fabrique ou qui vend des miroirs'. Esta definición contrasta con la que se propone en el DRAE 1837 para anteojero 'el que hace, compone y vende anteojos', ya que en francés el equivalente, documentado desde el siglo XV, según el TLFi, es lunetier, -ière 'celui, celle qui fabrique ou qui vend des lunettes, des instruments d'optique', que es la voz que se identificaría con el vocablo anteojero del español, puesto que se forma a partir de la base anteojos 'instrumento para ver desde lejos' (DRAE 1837). Estos datos reflejan, por tanto, que la inclusión de la voz en el Diccionario procede de la utilización de una traducción de una obra francesa de la segunda mitad del siglo XVIII en la que quizá se ha interpretado y traducido de forma incorrecta la palabra miroitier.

Se relaciona con este término curiosamente el sustantivo anteojera, incorporado en el Suplemento y que remite a la voz antojera que tiene dos significados, el primero de los cuales está relacionado con las gafas, ya que es 'la caja en que se tienen o guardan los antejos' y

14 En el corpus existen otros nombres de profesiones que se refieren a alguna área de especialidad científicotécnica, por ello, se han recogido en el apartado dedicado al léxico de especialidad (p. e. arqueólogo S; economato $S$; empresario, ria $\mathrm{S})$. 
el segundo se refiere a 'las guarniciones de las mulas de coche una pieza de vaqueta cosida a la parte exterior junto al ojo para que no vean por aquel lado'. Probablemente el primer significado mantenga relación con la incorporación de anteojero.

Poco se puede conocer sobre la voz canillaire 'canillero, por el que hace las canillas para los tejidos' — que desaparece en la 14. ' edición (1914)—, puesto que los corpus (COR$D E, C D E, C D H$ ) no la documentan. La terminación de esta palabra permite sospechar que se trata de una voz tomada de otra lengua, probablemente el catalán o el francés, pues en español no existe el sufijo de agente -aire (DECH, s. v. socaire) y los vocablos que lo contienen suelen ser préstamos. Tan extraña es esta terminación que son muy pocas las voces que la historia del $D R A E$ recoge con este sufijo y todas ellas proceden de otros idiomas (del germánico albaire, dancaire, del árabe ataire y alboaire, del aragonés borrapelaire y del catalán rabasaire y trabucaire).

Entre estos términos, el Suplemento también incluye la forma matarife 'oficial de matadero, que desuella y cuartea las reses', cuyo origen, según el $D E C H$ (s. v. matar), puede ser de procedencia jergal (calcatrife 'ganapán') o una voz creada a imitación de otras de origen árabe que contienen la misma terminación y designan oficios (alarife 'arquitecto', almojarife 'recaudador de contribuciones'). La primera documentación de esta voz según el CORDE y el CDH se halla, de nuevo (vid. cúbica), en José Somoza, seguramente también en la recopilación de sus Obras poéticas (1832-1837).

Además de los oficios anteriores, se incorporan dos derivados en -ista (folletista, helenista), un sufijo muy productivo en la creación de nombres de oficios, tal y como revela la historia de estas voces en el DRAE (Muñoz Armijo 2012). Folletista 'el escritor de folletos' en el $C D H$ se documenta por primera vez en un texto fechado entre 1820-1823 de Sebastián de Miñano (Sátiras y panfletos del Trienio Constitucional (1820-1823)). Esta voz podría ser derivado creado en italiano o derivado español sobre la base folleto que se empleaba para referirse a la 'gacetilla impresa que contiene regularmente las noticias del día' o al 'papel impreso de pocas hojas que se aplica regularmente al que es despreciable' y que es italianismo (procedente de foglietto) según el $\operatorname{DECH}($ s. v. hoja). En helenista se añade una segunda acepción referida al ámbito lingüístico ('perito en la lengua griega').

Finalmente, destacan otros como jalmero y yesquero. Se introduce jalmero como variante de enjalmero, cuya primera documentación se halla en la edición de 1817 , y se incorpora yesquero con dos acepciones, la primera relativa al ámbito del tabaco, que se comentará en el apartado 4.2.1.5., y en la segunda, designa 'el que fabrica o vende yesca'.

\subsubsection{Países y sus costumbres}

En el grupo semántico referido a países y sus costumbres se han incluido tanto gentilicios - calmuco, ca 'habitante de un distrito de la Tartaria'; cosaco, ca (1. acep) 'habitante de varios distritos de Rusia a las órdenes de un hettman o gobernador general'; guanches 'antiguos habitantes de las islas Canarias'; esquimal 'el natural del país situado cerca de las bahías de Hudson y Bafin'; hotentote, ta 'salvaje de un país inmediato al cabo de Buena Esperanza'-, como otras voces referidas a las costumbres y a aspectos culturales de otros países que la Corporación consideró que debía incorporar (caimacan 'dignidad entre los turcos'; dey 'jefe o príncipe de la regencia de Argel'; hospodar 'suprema dignidad en los principados de Moldavia y Valaquia'). Es probable que muchos de ellos entraran por 
conducto del francés, véase, por ejemplo, el caso de hotentote, que el Fichero General de la Real Academia documenta en la traducción española de la Historia Natural, general y particular del francés Georges-Louis Leclerc Comte de Buffon que lleva a cabo José Clavijo y Fajardo entre finales del siglo XVIII y principios del XIX.

Sobresalen los términos referidos a la costumbre de ejecutar a los reos de un modo especial, con una guillotina, voz que esta edición incorpora con el significado de 'máquina usada en Francia para cortar la cabeza a los reos' y el verbo que se emplea para describir esta acción (guillotinar 'quitar la vida en la guillotina'). Son, por tanto, préstamos del francés, como en tantas otras voces incorporadas en esta edición. El origen de estas dos palabras es especialmente interesante, ya que el sustantivo procede de la lexicalización de un nombre propio ("del fr. guillotine, derivado de Guillotin, nombre del que ideó esta máquina", DECH s. v.) para referirse a una máquina de ejecución durante la Revolución francesa.

Semánticamente relacionada con este grupo de términos se halla la voz naboria $(S)$, procedente del arahuaco de las Antillas según el $D E C H$ (s. v.), que se incorpora con el significado de 'el indio libre que se empleaba en el servicio doméstico', un término que se documenta ya desde los primeros textos de finales del siglo XV $(C D H, 1495)$ y principios del XVI ("1513, instrucciones a Pedrarias Dávila”, DECH s. v.) sobre las experiencias en las Indias.

\subsubsection{Tabaco}

Entre el léxico común existe un conjunto de voces relativas al ámbito del tabaco, una planta que tiene origen en América (Boyd Bowman 1971: 891), aunque el término, según el $D E C H(s . v$.), es incierto, ya que "consta que tabacco, atabaca y formas análogas (procedentes del ár. ţabbâq o tubbâq) se emplearon en España y en Italia desde mucho antes del descubrimiento del Nuevo Mundo". Entre las voces se recogen dos objetos relacionados con el hábito de fumar: se incorpora una segunda acepción para la voz petaca con el significado de 'caja para guardar el tabaco de humo, formada de paja, cuero u otra materia flexible' y yesquero, que se añade con dos acepciones y la primera se refiere también a un objeto para guardar el tabaco ('cañuto o caja en que los fumadores guardan la yesca'). Asimismo, se incluye el adjetivo fumador, ra 'el que tiene costumbre de fumar'. De entre las tres voces de este grupo destaca la acepción que se incluye en petaca -cuyo origen etimológico es el náhuatl "petlakálli 'caja de estera o de juncos', compuesto de pétlatl 'estera' y kálli 'casa"'- puesto que a pesar de que desde el siglo XVI hay testimonios de esta voz, no se difunde en España, según Ariza (2011: 17), hasta el siglo XIX.

\subsubsection{Vehículos de transporte}

Existe un grupo conformado por un conjunto de voces que se refieren a tipos de vehículos de transporte y proceden, en su mayoría, de otras lenguas. Cabriolé es galicismo y se incluye como nueva acepción al término referido a la indumentaria que ya contiene el Diccionario, significa 'especie de birlocho o silla volante'; carretela es 'coche ligero, que va cubierto o descubierto a arbitrio del que lo usa'; faeton es, según el $D E C H$ (s. v.), nom-

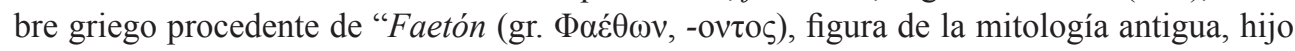
del Sol, que gobernó el carro de su padre" y se refiere en el DRAE 1837 a una "especie de 
coche largo con muchos asientos'. Finalmente, el caso de volanta que designa una 'especie de calesín muy ligero' ha sido examinado por Clavería (en prensa), una adición que es muy interesante porque está marcada con la abreviatura prov. de la Habana, una marca muy extraña en la práctica lexicográfica, según Clavería (en prensa), pues la marcación de las voces dialectales de procedencia americana no se realiza hasta las dos últimas ediciones (DRAE $1884,1899)$, ya que anteriormente el modo más frecuente de indicar la pertenencia de una voz al área del español americano era citándola en la definición. Llama también la atención esta palabra por el posible motivo que generó su inclusión en el Diccionario, Clavería (en prensa) supone dos fuentes que podrían ser el origen de esta nueva documentación tan especial, el Diccionario provincial de voces cubanas de Pichardo (1836), donde se define como "una de las especies de carruajes de lujo usados en la isla, igual al quitrín, con la diferencia que la parte superior es firme, á modo de caleza; cuyo nombre le daban antes en tierra dentro. || Véase CHUPA" o el Viaje de Perico Ligero al país de los moros del mejicano A. López Matoso de 1816 (López Morales 1971: 90) en el que se indica que "Bolantas son las q. los guachinangos dicen bolantes". Además, lo interesante de esta nueva incorporación es el hecho de ser un medio de transporte empleado en América, una cuestión que parece recurrente en todos los ámbitos semánticos no especializados.

\subsubsection{Otros}

En último lugar, se recoge un grupo de otros ejemplos en los que se han incluido las voces que se refieren a objetos cotidianos que no se asocian con los campos semánticos anteriormente descritos. En él se vuelve a confirmar la tendencia a la introducción de galicismos que se ha observado en cada uno de los apartados anteriores. Buró se define como 'papelera' y en su definición se explicita que es "voz tomada del francés" y se incorpora al campo semántico del mobiliario, un dominio en el que parece que también abundaron los galicismos (Álvarez de Miranda 2004: 1053; vid. p. e. canapé ya documentado desde el Diccionario de autoridades y sofá incorporado en la novena edición, 1843). Igualmente, tija 'la barrita o astil de la llave que media entre el anillo y el paletón' es de procedencia francesa (de tige, DECH, s. v. tibia). Se recoge, además, la voz anteojera, que se marca como anticuada y remite a antojera, que es 'la caja en que se tienen o guardan los anteojos' $\mathrm{y}$, como segunda acepción, significa 'en las guarniciones de las mulas de coche una pieza de vaqueta cosida a la parte exterior junto al ojo para que no vean'.

\subsubsection{El léxico de especialidad}

En el grupo de voces relativas al léxico de especialidad que forman parte del corpus se hallan hasta 130 nuevas incorporaciones referentes tanto a campos científico-técnicos (astronomía, arquitectura, astronomía, botánica, geología, geometría, historia natural, matemáticas, medicina, metalurgia, milicia, mineralogía, náutica y química) como a áreas humanístico-sociales y artísticas (comercio y economía, jurisprudencia, música, mitología, política, religión, teatro y poesía). La identificación y clasificación de las voces dentro de los lenguajes de especialidad es un tema complejo, tal y como explican Gutiérrez Rodilla (1998) y Pérez Pascual (2012), entre otros, puesto que el concepto y sus límites son borrosos $\mathrm{y}$ a veces un mismo término puede situarse en un lado y en otro en función del momento 
de la historia de la lengua que se analice y el contexto en el que se estudie. Pérez Pascual (2012: 207-208) se refiere, para ejemplificar este trasvase, a la terminologización que ha afectado a determinado vocabulario general al emplearse en el ámbito informático (ventana, ratón, programa) y al traspaso de un término de especialidad de un ámbito a otro (virus en medicina e informática). A pesar de esta complejidad y las dificultades que entraña la segmentación de los tecnolectos, ha parecido adecuado subdividir este apartado en un bloque en el que se incluyen los términos propios de la ciencia (§4.2.2.1.) y otro en el que se recogen aquellas voces propias de áreas concebidas como artes (\$4.2.2.2.) según las define el propio Diccionario.

\subsubsection{Léxico científico y técnico}

En este grupo se incluyen 113 voces propias de la ciencia y la técnica, una clasificación que se ha realizado teniendo en cuenta la concepción de la época sobre las áreas de especialidad, que se entendían bien como ciencias bien como artes, tal y como hacen Torruella y Huertas (2018) en su estudio sobre la edición de 1817. Así, por ejemplo, la música, manteniendo la concepción dieciochesca del término, se categoriza como una ciencia porque se define y entiende como tal a pesar de que desde finales del siglo anterior había empezado a contemplarse como una bella arte (música 'ciencia que trata de los sones armónicos' $D R A E$ 1837) y la química, que hasta la edición de 1822 se había descrito como un arte, pasa a formar parte de las ciencias en la edición de 1832 y se mantiene así también en la octava edición (química 'ciencia que componiendo y descomponiendo los cuerpos trata de averiguar la acción íntima de unos con otros, y las fuerzas con las que ejercen' DRAE 1837).

Las voces de este apartado se distribuyen en 17 áreas semánticas de especialidad que se encuentran contempladas en la lista de abreviaturas del Diccionario, aunque no todas presenten una marca diatécnica. De las más de cien voces y acepciones clasificadas en este grupo solo un tercio presenta marcación (33 aparecen marcadas) en 12 de los ámbitos: Anat. (anatomía), Arq. (arquitectura), Astro. o Astron. (astronomía) ${ }^{15}$, Arit. (aritmética), Bot. (botánica), Geom. (geometría), Hist. nat. (historia natural), Med. (medicina), Mil. o Milic. (milicia), Mús. (música), Náut. (náutica), Quím. (química). El resto de formas no presentan marca pero por su relación con la especialidad a la que pertenecen, según se ha deducido de la definición, se han incluido en la tabla 9. En este sentido, parece que la octava edición sigue los criterios de marcación del DRAE 1817, obra sobre la que Torruella y Huertas (2018: 255) estudiaron las voces de especialidad y para la que determinaron que la Corporación seguía un criterio de marcación pragmático, es decir, "las palabras se marcan como pertenecientes a un campo de especialidad no según su área temática sino según su nivel de especialidad".

En el $D R A E 1837$ creemos que el criterio que se podría haber seguido es el mismo, lo que podría explicar, por ejemplo, que caléndula, que remite a la voz maravilla para el significado de 'yerba', aparezca marcada como Bot. y, en cambio, no venga marcada la forma convólvulo "gusanillo que destruye las vides y se envuelve en sus hojas, llamado tambien

15 En la lista de abreviaturas de la octava edición solo se contempla la abreviatura Astron. pero en el corpus se ha encontrado un ejemplo de Astro. en la acepción nueva que el Suplemento incluye de la voz juno. 
revolton. [...] || Yerba llamada tambien clemátide, dafnoíde, vincaperrinca, voluble, etc.”. De igual modo, esto permite entender que la voz jalón aparezca marcada ("Geom. Palo o estaca que sirve para alinear los terrenos en las mediciones de los mismos y en el levantamiento de planos o de mapas") y, en cambio, no se marque geodesia ("parte de la geometría que trata de la medición de los terrenos"). En la tabla 9 se hallan las voces categorizadas en subáreas de especialidad:

\begin{tabular}{|c|c|}
\hline Ámbito de especialidad & Voces y acepciones \\
\hline Anatomía (3) & astrágalo ( $S$, acep.), carpo $\left(S, 1 .^{\mathrm{a}}\right.$ acep.), celular $\left(S, 1 .^{\mathrm{a}}\right.$ acep.) \\
\hline Arquitectura (3) & carpo $\left(S, 2 .^{\mathrm{a}}\right.$ acep.), luneto, $\underline{\text { socalzar }}^{16}(S)$ \\
\hline Aritmética (2) & $\underline{\operatorname{aritmetico}, c a}(S$, acep.), billon $(S)$ \\
\hline Astronomía (2) & ceres $(S)$, juno $(S$, acep.) \\
\hline Botánica (7) & $\begin{array}{l}\text { aristoloquia }(S, \text { acep. }) \text {, calendula }(S) \text {, calisaya }(S) \text {, capsular }(S) \text {, } \\
\text { carquexia }(S) \text {, celular }(S) \text {, convólvulo }\end{array}$ \\
\hline Geografía (2) & continental $(U / S), \underline{\text { delta }}$ \\
\hline Geometría (2) & jalon, geodesia $(S)$ \\
\hline Historia natural (14) & $\begin{array}{l}\text { baharí (acep.), bambú o bambuc }(S), \underline{\text { bergamoto }}(S, \text { acep. }), \underline{\text { brécol, lera }} \\
(S), \underline{\text { claudia }}(S), \underline{\text { colza }}(S), \underline{\text { copudo }}, \text { crisálida }(U / S), \underline{\text { encornadura }}(S), \\
\text { estalactitas }(S), \underline{\text { híbrido }} \text { incubacion }(S) \text {, peón }(S, \text { acep. }), \underline{\text { upupa }}\end{array}$ \\
\hline Jurisprudencia (2) & jurado (acep.), legislatura \\
\hline Medicina (13) & 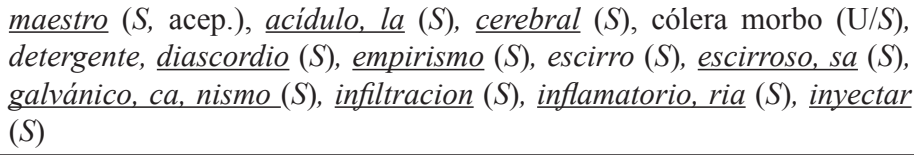 \\
\hline Metalurgia $^{17}(3)$ & clisar $(S$, acep.), docimástica $(S)$, fuslina \\
\hline Milicia (10) & $\begin{array}{l}\text { agá }(S \text {, acep.), cañas (correr) }(S) \text {, capona }(S \text {, acep.), botasilla, chacó, } \\
\text { chambelan, fusilar }(S) \text {, guerrillero }(S) \text {,redoblar (acep.), teutónico, ca }(S)\end{array}$ \\
\hline Mineralogía (4) & cuarzoso, sa, chorlo, galena $(S)$, grafito $(S)$ \\
\hline Música (12) & $\begin{array}{l}\text { albogue (acep.), apagador, dora (acep.), arpejio }(S), \text { cantata }(S), \\
\text { concertante }(U / S), \underline{\text { crótalo }}, \underline{\text { do }}(S, \text { acep. }), \text { dueto, fagot }(S), \text { filarmónico, } \\
(S), \underline{\text { cambras chinescas }}(s . \text { v. sombra acep.), violoncelo o violonchelo }(S)\end{array}$ \\
\hline Náutica (10) & 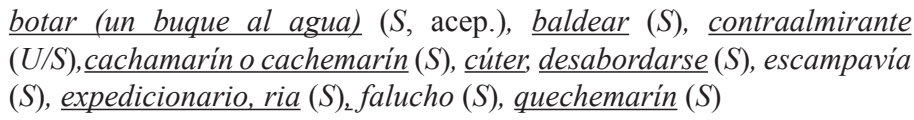 \\
\hline
\end{tabular}

16 El subrayado indica que esa palabra no presenta marca en el Diccionario y que se ha relacionado con el ámbito de especialidad por su significado.

17 Hasta la edición del DRAE 1884 no se encuentra una marca para el vocabulario referido a la metalurgia. Sin embargo, se ha considerado que, por su uso, estas voces deberían estar incluidas en este grupo. 


\begin{tabular}{|c|c|}
\hline Ámbito de especialidad & Voces y acepciones \\
\hline Química (4) & $\underline{\text { cosmético }}(S)^{18}$, eflorescencia, florescencia quinina \\
\hline $\begin{array}{l}\text { Otras voces sobre la } \\
\text { ciencia y la técnica en } \\
\text { general (12) }\end{array}$ & $\begin{array}{l}\text { arqueología }(S), \underline{\text { arqueólogo }}(S), \underline{\text { bimembre }}, \underline{\text { calculable, }}, \underline{\text { centrifugo, ga }} \\
(S), \underline{\text { centripeta }}(S), \underline{\text { ciencias }} \text { (exactas) }(S), \underline{\text { crepuscular }}, \underline{\text { enjuagatorio }} \text {, } \\
\text { gaseoso, sa }(S), \text { geognosia }(S), \underline{\text { higiene }}(S)\end{array}$ \\
\hline
\end{tabular}

Tabla 9. Voces del lenguaje de especialidad científico en el DRAE 1837.

Como se puede observar a partir del análisis de los datos de la tabla 9, los ámbitos especializados en los que se recogen más incorporaciones (entre 10 y 14) son la historia natural, la medicina, la música, náutica y la milicia, que son las áreas a las que se les va a dedicar un análisis más detallado en los siguientes párrafos.

\subsection{Historia natural}

El grupo de voces y acepciones referidas la historia natural —entendida como la 'descripción de las producciones de la naturaleza en sus tres reinos animal, vegetal y mineral' (DRAE 1837, s. v. historia) - es heterogéneo, en él se hallan nombres de frutas (claudia), verduras (brécol, brecolera, colza), árboles y plantas (bambú o bambuc, bergamoto), animales (bahari) procedentes de otras culturas y otros nombres (crisálida, estalactitas, híbrido, incubación, peón) y adjetivos (copudo) sobre realidades propias de las ciencias naturales. De todas ellas solo dos aparecen con la marca hist. nat. (crisálida y estalactitas) $\mathrm{y}$, en comparación con ediciones anteriores - como la 5. a y la 6 . $^{\mathrm{a}}$-, se observa un descenso destacable en el número de voces relativas a las ciencias naturales a las que los suplementos habían dedicado un espacio importante (cfr. Huertas 2014 y Gómez de Enterría 2018).

En lo que se refiere al reino vegetal, se incorporan nombres de frutas y plantas procedentes de otras culturas. La claudia se define como una 'especie de ciruela redonda, de color claro muy jugosa y dulce' y, según el $D E C H(s . v$.), procede de la "abreviación del fr. prune de la reine Claude íd., así llamada por el nombre de la esposa de Francisco I de Francia". La forma brécol — cuya definición en el DRAE 1837 remite a bróculi- "resulta de brócul cruzado con bretón, nombre de otra variedad de col; brócul viene del it. bròccoli 'brécol', diminutivo plural de brocco 'retoño', y éste deriva del lat. BRoccus 'que tiene los dientes salidos para afuera" ( $D E C H$ s. v.). Asimismo, el origen de colza, que según el mismo diccionario etimológico es extranjerismo poco usado, hay que buscarlo en una

18 Cosmético, que no aparece marcada en la obra como voz de la química, se define como 'preparación para hermosear la tez'. No se recoge en el $D E C H$ y solo presenta una documentación en el Fichero General de la Real Academia que pertenece a finales del siglo XVIII, concretamente en la obra de Memorias instructivas y curiosas sobre agricultura, comercio, industria, economía, chymica, botánica é historia natural, \&c: sacadas de las obras que hasta hoy han publicado varios autores extrangeros (1778) de Miguel Gerónio Suárez en el que la forma léxica aparece en un contexto que parece poder interpretarse como voz química "disolviendo el bismuth por medio de accido nitroso, y precipitándole [...] se saca una cal blanca [...] con que después de bien endulzorada se compone un buen cosmético paras las Damas" (Suárez 1778: 2C-V-26). En el CDH, en cambio, la primera documentación pertenece a 1825 y se halla en un texto de Leandro Fernández de Moratín (Cartas de 1825). Según el TLFi (s. v. cosmétique) es préstamo del griego y quizá podría haber llegado por conducto del francés al español. 
voz que llega al español a través del francés (colza) y pertenece al neerlandés (“koolzaad, propiamente 'simiente (zaad) de col (kool)"' DECH, s. v.). Otros préstamos no procedentes del francés se refieren a plantas, por un lado, bergamoto 'árbol, especie de limonero, que produce un fruto del mismo nombre, diferente del limón común en su mayor tamaño, sabor algo amargo, y olor suave y delicado' cuyo origen se halla en el turco y llega al español a través del italiano (bergamotta, bergamotto) y, por otro lado, el término bambú 'especie de junco o caña de Indias que se emplea en bastones y otros usos', que aparece recogido junto a la variante gráfica bambuc, y que, según el $D E C H$ (s. v.), llega al español a través del portugués y tiene origen en el maratí y guzaratí. Se documenta desde principios del siglo XVII $(D E C H, s$. v.) y la recoge ya Terreros (1786-1787), aunque los primeros testimonios del $C D H$ son del primer cuarto del siglo XIX.

Las incorporaciones referidas al reino animal se refieren a aves, como es el arabismo bahari 'especie de halcón procedente de países septentrionales' o el latinismo upupa, cuya definición remite a la voz patrimonial abubilla, y del sustantivo incubación 'el acto de empollar los huevos la gallina y otros ovíparos'. Asimismo, destacan otras dos voces: una forma parasintética para describir una parte de un animal (encornadura 'la forma o disposición de los cuernos del toro, ciervo, etc.') y un sustantivo latino que llega al español por conducto del francés (DECH, s. v. híbrido) y que sirve para describir aquellos animales que surgen de la mezcla de dos especies (híbrido 'animal procreado por dos distintas especies, como el mulo'). Este sustantivo se recogió desde 1803 (4. ${ }^{\mathrm{a}}$ ed.) hasta 1832 (7. a $^{\circ}$ ed.) en femenino (híbrida) con los mismos significados ${ }^{19}$, y es en la octava edición cuando la forma se cambia al masculino como se aprecia en la tabla 10:

\begin{tabular}{|c|c|}
\hline$D R A E(1803)$ & $D R A E(1837)$ \\
\hline $\begin{array}{l}\text { HÍBRIDA. s. m. p. us. Animal nacido de dos } \\
\text { especies diferentes, como el mulo. Ibrida, ibris. } \\
\text { HÍBRIDA. met. adj. que se aplica á las voces } \\
\text { formadas, ó compuestas de dos idiomas diferentes; } \\
\text { como Monóculo. Ibrida. }\end{array}$ & $\begin{array}{l}\text { HÍBRIDO. c. Animal procreado por dos } \\
\text { distintas especies, como el mulo. Hibridos. ॥ } \\
\text { met. adj. que se aplica á las voces formadas } \\
\text { ó compuestas de dos idiomas diferentes, como } \\
\text { monóculo. Hibridus. }\end{array}$ \\
\hline
\end{tabular}

Tabla 10. Hibrida e híbrido en el DRAE (1803) y en el DRAE (1837).

Sobre híbrida el $C D H$ ofrece una primera documentación con el significado de mezcla de diferentes especies referida a personas y no a animales en un texto de 1648 de Juan de Solórzano y Pereira (Política indiana) y, en concreto, se refiere a los que nacen de progenitores de distintas razas en Indias:

Pero dexando yá los Criollos, y viniendo á tratar de los que llaman Mestizos, y Mulato, de que hay gran copia en las Provincias de estas Indias, lo que se me ofrece que decir es, que tomaron el nombre de Mestizos, por la mixtura de sangre, y Naciones que se juntó á engendrarlos, por donde los Latinos los llamaron Varios, é Hibridas, según Paleoto, y otros Autores.

19 Los pequeños cambios que se introducen en la definición de esta voz desde su primera documentación en el $D R A E$ y que se observan en la tabla 10 se producen en la edición de 1817 (5. ${ }^{\mathrm{a}}$ ed.). 
Todos los ejemplos que ofrece el CDH de híbrida del siglo XVII y XVIII se corresponden con el mismo significado de Juan de Solórzano, mezcla de razas en Indias. Hasta 1797 no se recoge en este corpus un uso relativo a la historia natural en José Antonio Cavanilles (Observaciones sobre la historia natural, geografía, agricultura, población y frutos del reyno de Valencia). Sin embargo, para la forma masculina (híbrido) el corpus no recoge datos hasta unos años más tarde de la publicación de la octava edición, en 1847 (Juan Valera, Correspondencias). Otro autor del siglo XVIII que ofrece primeras documentaciones de las voces incorporadas en el DRAE 1837 en el $C D H$ es Benito Jerónimo Feijoo (1728, Theatro crítico universal, o discursos varios en todo género de materias, para desengaño de errores comunes, vol. 2), en cuya obra se testimonia por primera vez el término incubación con el significado relativo a las aves.

Crisálida es un helenismo ("tomado del gr. $\chi \rho v \sigma \alpha \lambda \lambda i \varsigma,-i \delta o \varsigma$ íd., derivado de $\gamma \rho v \sigma o ́ \varsigma$ por el color dorado que tienen muchas crisálidas" $D E C H$, s. v. criso-) que aparece ya en el diccionario de Terreros (1786-1793).

En una revisión más detallada de esta edición podrían estudiarse las definiciones de las entradas de esta área de especialidad para ver si continuaron sistematizándose o si se modificaron para hacerlas más descriptivas como había ocurrido en la quinta edición (Gómez de Enterría 2018: 294).

\subsection{Medicina}

Se incorporan palabras de diverso tipo, que se refieren tanto a enfermedades (cólera morbo 'enfermedad aguda [...]', inflamatorio 'lo que causa inflamación o procede de ella', escirroso, $s a$ 'lo que padece o está afectado de escirro') como a medicamentos (detergente 'lo que limpia o purifica', diascordio 'confección medicinal, cuyo principal ingrediente es la yerba llamada escordio') y prácticas médicas (empirismo 'modo de curar fundado solo en meras prácticas'). Según datos del $\mathrm{DECH}$, son cultismos o derivados cultos en muchos casos (detergente, diascordio, escirro, escirroso, inflamatorio, ria) y algunos se documentan ya desde el siglo XVII. Las palabras galvánico, $c a$ — que, como se ha comentado en apartados anteriores (§ 4.1.), no incluyen definición - se han incorporado en el ámbito de la medicina porque la voz galbanismo (que es variante formal de galvanismo) está marcada como voz propia de la medicina ya desde su primera inclusión en la edición de 1822 ("Med. La propiedad de excitar movimientos espasmódicos en los nervios y músculos"). Entre todas las voces destaca, por ser portadora de la marca ant., la acepción que se incluye sobre maestro como sinónimo anticuado de cirujano.

\subsection{Náutica}

La cantidad de voces náuticas (10) añadidas no sorprende, pues es un grupo léxicosemántico que siempre ha tenido una alta representación en la historia de las ediciones del DRAE por la vinculación que algunos de los académicos de principios de siglo XIX (Martín Fernández de Navarrete y José Vargas Ponce) tuvieron con este ámbito del saber científico-técnico (Carriazo 2018: 342-343). Por ello, en esta edición tienen también una presencia relevante los términos que se relacionan con este dominio y quizá podrían haberse tomado del Diccionario maritimo español, que además de las definiciones de las voces con sus equivalentes en francés, inglés e italiano, contiene tres vocabularios de 
estos idiomas con las correspondencias castellanas que se publicó en 1831, ya que todos se hallan documentados en esta obra. Este grupo incluye principalmente voces referidas a tipos de embarcaciones (cúter, escampavía, falucho, cachamarín o cachemarín) que suelen proceder de otras lenguas como el inglés (cachamarín y sus variantes cachemarín y quechemarín, y cúter) - aunque pudieron llegar a través del francés (quechemarín, tomado del "fr. caiche y éste del ingl. ketch", DECH, s. v.) -; el francés (contraalmirante, desabordarse, falucho); y el italiano (escampavía). En este grupo se incluyen también cargos (contraalmirante 'en la marina inglesa y de otras naciones equivalentes a jefe de escuadra' $U / S$ ) y algunas acciones propias de este sector (baldear 'regar las cubiertas de los buques con los baldes o cubetas que se usan en ellos, a fin de refrescarlas y limpiarlas'). Entre las acciones sobresale la expresión pluriverbal botar (un buque al mar) 'echarle del astillero al mar' no solo por el origen francés de la voz botar sino porque el significado al que alude es propio del español de América según el $D E C H$ (s. v.):

Significó antiguamente 'lanzar, arrojar, tirar', con aplicación a cualquier objeto (botar las orinas en Alex.), extensión semántica hoy conservada casi en toda América (botar una piedra, botar el pañuelo) y en las hablas leonesas y gallegoportuguesas, así como en el vasco bota. En el resto de España el vocablo alcanzó menor vitalidad y pronto tendió a tomar el matiz de 'arrojar con violencia'.

Parece muy posible suponer que la fuente que se tomó como referencia para la inclusión de casi todas estas voces fuera el Diccionario marítimo español (1831) —de ahora en adelante $D M E$ - por varias razones: por un lado, Martín Fernández de Navarrete, que era uno de los académicos de número más antiguos, fue promotor de la publicación de la obra (Carriazo 2018: 339); por otro lado, casi todas las voces aparecen documentadas en este diccionario (excepto expedicionario, ria); y, finalmente, muchas de las definiciones del DRAE (1837), aunque no son exactas a las del $D M E$ (1831) porque hay cambios ortográficos y formales (cachamarina, contra-almirante) y reducción de contenidos (escampavía), guardan cierta similitud con ellas. Véase, por ejemplo, el caso de cúter entre los que se recogen en la tabla 11:

\begin{tabular}{|c|c|}
\hline$D M E$ (1831) & $D R A E(1837)$ \\
\hline $\begin{array}{l}\text { BALDEAR. v. a. Nav. Lavar las cubiertas con el } \\
\text { agua que se saca del mar y arroja sobre ellas con } \\
\text { los baldes. }\end{array}$ & $\begin{array}{l}\text { BALDEAR. a. Regar las cubiertas de los buques } \\
\text { con los baldes ó cubetas que se usan en ellos, á } \\
\text { fin de refrescarlas y limpiarlas. }\end{array}$ \\
\hline $\begin{array}{l}\text { BOTAR. [...] Botar al agua un buque. V. esta } \\
\text { frase en agua. } \\
\text { AGUA. [...] Botar, echar ó lanzar al agua un } \\
\text { buque: hacer un resbale por la grada al agua } \\
\text { después de construido ó carenado. }\end{array}$ & $\begin{array}{l}\text { BOTAR. [...] Botar un buque al agua fr. Náut. } \\
\text { Echarle del astillero al mar. }\end{array}$ \\
\hline $\begin{array}{l}\text { CACHAMARINA ó CACHEMARIN. s. m. el } \\
\text { segundo y f. el primero. } A N \text {. Embarcacion chica } \\
\text { de dos palos, con vela al tercio, una pequeña } \\
\text { mesana á popa, algunos foques en un botalon á } \\
\text { proa, y gavias volantes en tiempos bonancibles. } \\
\text { Úsase en las costas de Bretaña, y en las del norte } \\
\text { de España, donde tambien se llama quechemarin. }\end{array}$ & $\begin{array}{l}\text { CACHAMARIN Ó CHACHEMARIN. m. } \\
\text { Embarcacion chica de dos palos, con velas al } \\
\text { tercio, algunos foques en un botalon á proa, y } \\
\text { gavias volantes en tiempos bonancibles. Úsase } \\
\text { en las costas de Bretaña y en la de Cantabria, } \\
\text { donde tambien se llama Quechemarin. }\end{array}$ \\
\hline
\end{tabular}




\begin{tabular}{|c|c|}
\hline$D M E(1831)$ & $D R A E(1837)$ \\
\hline $\begin{array}{l}\text { CONTRA-ALMIRANTE. s. m. Nav. V. Almirante } \\
=\text { Fr. Contre-amiral. }=\text { Ing. Rear-admiral. }=\text { It. } \\
\text { Contra-amiraglio. }\end{array}$ & $\begin{array}{l}\text { CONTRALMIRANTE. m. En la marina inglesa } \\
\text { y de otras naciones equivalente á jefe de escuadra. }\end{array}$ \\
\hline $\begin{array}{l}\text { CUTER. s. m. } A \text {. } N \text {. Nombre ingles adoptado en } \\
\text { nuestro idioma, y propio de una embarcacion con } \\
\text { velas al tercio, una cangrejilla ó mesanilla en un } \\
\text { palo chico á popa y varios foques. = Fr. } \text { Cutter. } \\
\text { Ing. } \text { Cutter. = It. } \text { Cutter. }\end{array}$ & $\begin{array}{l}\text { CÚTER. m. Embarcacion con velas al tercio, } \\
\text { una cangreja ó mesana en un palo chico colocado } \\
\text { hácia popa, y varios foques. Es nombre tomado } \\
\text { del inglés y adoptado por los franceses e italianos. }\end{array}$ \\
\hline $\begin{array}{l}\text { DESABORDARSE. v. r. Man. Volver á separarse } \\
\text { despues de abordado con otro buque. Dícese mas } \\
\text { comunmente desatracarse. = Fr. Desaborder. }= \\
\text { It. Desabordarsi. }\end{array}$ & $\begin{array}{l}\text { DESABORDARSE. r. Separarse una } \\
\text { embarcacion después de haber abordado con } \\
\text { otra. }\end{array}$ \\
\hline $\begin{array}{l}\text { ESCAMPAVÍA. s. f. Nav. Segun algunos de los } \\
\text { diccionarios consultados, es un barco latino, ó de } \\
\text { otra clase, pero chico y velero, que suelen llevar } \\
\text { en su conserva las embarcaciones guarda-costas ó } \\
\text { los corsarios para que reconozca las calas de poco } \\
\text { fondo, dé cazas y haga descubiertas avanzadas. } \\
\text { Dícese también mosca. = It. Scampavia. }\end{array}$ & $\begin{array}{l}\text { ESCAMPAVÍA. f. Náut. Embarcacion velera } \\
\text { pequeña y á propósito para hacer descubiertas, } \\
\text { dar avisos y reconocer las costas. }\end{array}$ \\
\hline $\begin{array}{l}\text { FALUCHO. s. m. A. N. Embarcacion pequeña, } \\
\text { de un solo palo muy inclinado hácia proa, y con } \\
\text { vela latina. = Fr. Falouche. = Ing. Felucco. = It. } \\
\text { Faluccio. }\end{array}$ & $\begin{array}{l}\text { FALUCHO. m. Náut. Embarcacion costanera } \\
\text { con una vela latina. }\end{array}$ \\
\hline $\begin{array}{l}\text { QUECHEMARIN. s. m. A. N. } V \text {. Cachamarina } \\
\text { ó cachemarin. }\end{array}$ & QUECHEMARIN. m. CACHAMARIN. \\
\hline
\end{tabular}

Tabla 11. Comparación de las entradas de la náutica del DME (1831) y el DRAE (1837).

Además de la relación que parece evidente entre las dos obras, el DME proporciona datos importantes sobre la etimología y los equivalentes ${ }^{20}$ de algunas voces que no proporciona el $D E C H$ y siguen reflejando que buena parte del léxico que se incorpora en la octava edición procede de otras lenguas y, en especial, del francés.

\subsection{Música}

Los términos sobre la música merecen especial atención porque constituyen un grupo aparte respecto al resto de las incorporaciones que se analizan en este apartado. Diversas de las voces proceden del italiano (arpejio — que se escribirá arpegio a partir de la 9. ${ }^{\mathrm{a}}$ ed.

20 En el Prólogo (DME 1831: XXXIII) se explica que la información que aparece al final de algunas entradas corresponde a su origen en el caso de que sean adoptadas: "En cuanto á las correspondencias extranjeras se han omitido todas las que no se traducen voz por voz; y las adoptadas van á continuacion de la definición en el sentido á que en rigor equivalen, ó bien al fin del artículos cuando tienen aplicación á todas las acepciones que comprende". 
(1843) - ${ }^{21}$, dueto, cantata, violoncelo o violonchelo), lo que implica la influencia de una lengua distinta respecto a los otros ámbitos en los cuales predominan o bien las voces de origen francés o bien las voces de lenguas amerindias. El influjo y la preeminencia del italiano en la historia moderna de la música se hacen evidentes en este ámbito, algo que ya han notado diversos investigadores en ocasiones anteriores (Álvarez de Miranda 2009). Justiniano (2014: 31) se refiere al moderno estilo musical italiano como lingua franca, lo que convirtió, a su vez, a la lengua italiana en el idioma de la música por excelencia. Según Justiniano (2017: 210-212), el siglo XVIII es una época importantísima en el desarrollo de la música y de su historia, pues pasa de ser entendida y concebida como una ciencia a un arte, como se ha comentado en la introducción de este apartado (vid. §4.2.2.1.). Esto tiene un reflejo lingüístico significativo y puede advertirse en la cantidad de diccionarios de la música que desde principios de siglo XIX se empiezan a preparar, aunque el primero no se publica hasta 1852 (Antonio Fargas y Soler, Diccionario de música).

Las voces y acepciones incorporadas se refieren tanto a instrumentos (fagot, violoncelo o violonchelo, crótalo), como a composiciones musicales (cantata 'composición métrica acompasada para la música'; concertante 'que se aplica a la pieza compuesta de dos o más voces entre las cuales se distribuye el canto') y otras cuestiones relativas tanto al receptor o espectador (filarmónico, ca 'el muy aficionado a la música') como a los intérpretes (arpejio 'modo de producir sucesiva y rápidamente todos los sonidos de una postura en lugar de darlos a un tiempo').

Además de la adición de estos lemas, también se añaden nuevas acepciones muy relevantes tanto en la historia de la música como en la historia del léxico de esta arte. En la voz do se incluye la acepción referida a la nota musical ('primera voz de la escala musical, que en el sistema moderno sustituye al ut'). Esta nota anteriormente se denominaba $u t$, designación que le había otorgado Guido d'Arezzo en el siglo XI (Grabner 2001:60). El nombre de las notas se corresponde con las sílabas iniciales de cada verso de un himno a San Juan ( $U t$ queant laxi, Re sonare fibirs, $M i$ ra gestorum, $F a$ muli tuorum, Sol ve polluti, $L a$ bii reatum). En el sistema musical moderno se sustituye ut por do (además de añadirse la nota si para el séptimo grado) para facilitar el solfeo. El origen de este cambio podría hallarse en la primera sílaba su apellido del italiano Giovanni Battista Doni (Buroni 2015: 108 , nota 83), aunque existen otras hipótesis, como, por ejemplo, la que sustenta que es la primera sílaba de la palabra latina dominus. También se agregan acepciones nuevas (Blanco 2014) en otras entradas como albogue (2. acep.) 'instrumento compuesto de dos chapas de azofar, en forma de platillos', apagador, dora (3. a acep.) 'en varios instrumentos de cuerda cada uno de los macitos cubiertos de cuero que corresponden a cada tecla y sirven para apagar el sonido' y sombras chinescas (s. v. sombra) 'espectáculo en que se presentan figurillas en acción junto a un foro o cortina de papel blanco, iluminada por la parte opuesta a los espectadores'. En este grupo podría incluirse también la acepción que se añade a la voz redoblar (4. a acep.) 'tocar redobles en el tambor', sin embargo, esta palabra aparece con la marca Mil., por ello, se ha tenido en cuenta como voz militar aunque se refiera a la forma en la que se toca un instrumento musical.

21 Este ejemplo muestra la heterogeneidad en la aplicación de los criterios ortográficos recogidos en la $O R A E$ 1820 y sobre los que la Corporación manifestó su preocupación en el Prólogo, puesto que, según los principios ortográficos, esta palabra debería mantener su ortografía original (procede "del it. arpeggio, derivado de arpeggiare 'tocar el arpa"”, DECH s. v. arpa), tal y como se hizo con la aplicación del cambio de villar a billar (vid. §4.2.1.2.). 


\subsection{Milicia}

Las voces sobre la milicia suponen un número de incorporaciones similar al de la música y sigue, como en otros campos, la tendencia a la incorporación de voces procedentes de otras lenguas y muy especialmente del francés (p. e. botasilla (del fr. boute-selle), chambelan (del fr. chambellan)) o de otras lenguas a través del francés (chacó "tomado del húngaro csákó [...] por conducto del fr. schako", DECH, s. v.). Para fusilar "pasar por las armas con el fusil', por ejemplo, puede suponerse también un origen francés (fusiller) —a pesar de que en el $D E C H$ (s. v.) no se indique-, ya que la primera documentación, según el $C D H$, se halla en un texto de Antonio de Capmany de 1808 (Centinela contra franceses, segunda parte) y que el origen de fusil es también el francés. Otro ejemplo de la influencia y de la necesidad que en esta edición parece existir por incluir todo lo referente a otras culturas es el adjetivo teutónico, ca, que se define como voz que se 'aplica a una orden militar de Alemania, y a los caballeros de la misma'. De todas las voces de este campo, solo se ha encontrado botasilla (con la forma botasela) documentada en el DICTER, por ello, quizá, cabría pensar que se documentan en textos de finales del siglo XVIII y principios del XIX.

\subsection{Otros}

Además de los casos anteriores, en distintos ámbitos científicos, como la botánica y la química, se incorporan nombres de realidades naturales, algunas con aplicaciones medicinales, procedentes de América. La calisaya, por ejemplo, se incluye en el ámbito de la botánica porque aparece distinguida como tal en el Diccionario (con la marca bot.), aunque por su definición pudiera incluirse también en el grupo de la historia natural. Se trata de 'una de las especies de quina más medicinales', cuya etimología es dudosa, según los datos del DECH (s. v.), puesto que podría proceder o bien "de nombre del indio que reveló las propiedades curativas de la quina al gobernador de Loja (Ecuador), López de Cañizares”, o bien, "según la Acad. (1936) vendría del nombre de una colina de Bolivia".

Asimismo, la quinina — que se ha incluido en el grupo de la química (Garriga 2003), aunque también se podría considerar voz propia de la historia natural, como el caso anterior- es derivado de quina, un término que formaba parte de la nomenclatura desde el Diccionario de autoridades y se define como el 'extracto de la quina, en el cual queda esta corteza reducida a la parte medicinal'. Es en la octava edición donde, según Díez de Revenga (2013: 45), se define de este modo por primera vez la quinina. Aunque algunos autores afirman que quina es voz de origen quechua, el $\operatorname{DECH}(s . v$.) considera que es de etimología incierta: "voz propagada desde el Perú, junto con este medicamento americano, pero es dudoso que el nombre sea de origen quichua". En Garriga (2003: 110) se afirma que esta es la primera denominación de un alcaloide que entra en el Diccionario, sin embargo, parece que es, en sus palabras, "un caso esporádico", ya que "no aparece ningún otro hasta la 11. edición, cuando junto a morfina se incorpora nicotina, y hay que esperar a la 12. a edición para encontrar las

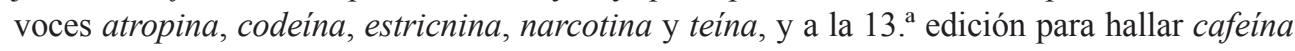
y anilina". De este término sobresale la primera documentación que aporta el $C D H$ en José Somoza y la voz aparece en la obra La minuta de la comedia (1834): "Conténtase con que se le coloque en el humilde andén de los sainetes. Sin embargo de que hay algún sainete que es (aunque mal comparado) como la quinina, mejor que la quina misma". 


\subsubsection{Otro léxico de especialidad}

En este apartado se recoge un conjunto de formas (vid. tabla 12) que se incorporan a la octava edición y que no se incluyen en el grupo de las ciencias.

\begin{tabular}{|c|c|}
\hline Ámbito de especialidad & Voces y acepciones \\
\hline Comercio y la economía (10) & $\begin{array}{l}\text { adeudo }(S), \underline{\text { avalúo }}(S), \underline{\text { cargareme }}(S), \underline{\text { catastro }}(S, \text { acep. }), \\
\text { contabilidad, economato }(S), \text { economizar }(S) \text {, efectivo (en) }(S, \\
\text { acep.), empresario, ria }(S) \text {, envio }\end{array}$ \\
\hline Mitología (4) & $\begin{array}{l}\text { elíseos o elisios (campos) }(S) \text {, faunos ( } S \text {, acep.), hamadriada, } \\
\text { oreada }\end{array}$ \\
\hline Política y sociedad (6) & $\begin{array}{l}\text { club }(S), \underline{\text { constitucional }}(U / S), \text { demócrata, imperar }(S \text {, acep.), } \\
\text { colonial }(S), \text { colonizar }(S)\end{array}$ \\
\hline Religiones (11) & $\begin{array}{l}\text { alminar, apóstol }(S \text {, acep.), apoteosis }(S) \text {, archimandrita }(S, \\
\text { acep. }), \underline{\text { bardo }}(S), \text { bautista }(S), \underline{\text { deuteronomio, episcopado }}(S), \\
\underline{\text { matrimonio }} \text { (acep.), propaganda, timiama }(S \text {, acep. })\end{array}$ \\
\hline Teatro (2) & entreacto $(S)$, escenario $(S)$ \\
\hline
\end{tabular}

Tabla 12. Voces de otros lenguajes de especialidad del DRAE 1837.

Sobresalen, como puede observarse, las voces referidas al comercio y a la política, algo que seguramente mantiene una relación directa con los cambios históricos, sociales y políticos que se producen en la primera mitad del siglo XIX (Álvarez de Miranda 2004: 1044).

\subsubsection{Comercio y economía}

En el sector del comercio y la economía las incorporaciones son notables y comparables a las de otros ámbitos relativos al saber científico que se han analizado en las páginas anteriores (medicina, historia natural, música, etc.), aunque — según De Hoyos (2007: 252253) - no es hasta la edición de 1884 cuando este campo aparece bien diferenciado. Las voces y acepciones añadidas hacen referencia tanto a transacciones y acciones económicocomerciales (avalúo, economizar, en efectivo, envío, cargareme, adeudo), como a profesiones (economato, empresario, ria). De todas ellas, solo una presenta la marca Com., se trata de envio 'la acción y efecto de enviar, remesa'.

Diversas de las palabras de este ámbito presentan primeras documentaciones entre finales del siglo XVIII y principios del siglo XIX en el CORDE. Por ejemplo, la expresión pluriverbal en efectivo 'el dinero en metálico' tiene su primera documentación en un texto de 1791 de Gaspar Melchor de Jovellanos (Diario de 1791); así como la voz empresario 'el que toma a su cargo alguna empresa o negociación en que intervienen personas, poniendo los fondos necesarios para ella, y recayendo en él las pérdidas o las ganancias que resulten' que aparece por primera vez en un texto de Francisco de Miranda (1785-1786, Diario de viajes (viaje por Italia y Rusia)) y en autores y textos sobre economía y sociedad (Manuel Bretón de los Herreros, Ramón de Mesonero Romanos, Mariano José de Larra, etc.). Se trata de un italianismo como otros de los que penetran en el léxico económico español como agio o bancarrota (Álvarez de 
Miranda 2009). El Fichero General, además, recoge una documentación de empresario en la obra de economía política del Marqués del Valle de los Herreros (1833). Esto demuestra que la rapidez de los movimientos sociales y políticos se refleja en la lengua y en la aceptación de los términos para concebirse como parte de la lengua común (Gómez de Enterría 1996).

Gómez de Enterría (1992) explica que el comienzo de la Revolución Industrial en Gran Bretaña marca el inicio del uso de un nuevo vocabulario, que se expande y modifica rápidamente, asociado directamente a los cambios que se estaban produciendo en materia económica y mercantil. Señala que durante el siglo XIX el lenguaje de la economía continúa evolucionando hasta afianzarse en el siglo XX. Y, en este contexto, la historia del vocabulario económico en el $D R A E$ permitiría ver de qué modo se produce esta evolución. En la 5. ${ }^{\mathrm{a}}$ edición (1817), por ejemplo, De Hoyos (2018) advierte que la incorporación de este tipo de voces tiene una importancia menor respecto a otras, pues solo incorpora una veintena de voces, una cifra muy baja si se compara con las más de 1200 adiciones que incluye esa edición, ya que supone un $1,6 \%$ del total del corpus. Si se contrastan estas cifras con las que se han recogido para la octava edición, puede afirmarse que en 1837 el léxico del comercio y la economía tiene un poco más de relevancia, como reflejan las 10 voces nuevas entre los 262 lemas nuevos, lo que supone un 3,8\% del total de incorporaciones.

\subsubsection{Política y sociedad}

La incorporación de voces relacionadas con la política y la sociedad muestran los cambios del momento en materia de relaciones internacionales. La voz club, procedente del inglés $(D E C H, s . v$.), se incorpora con el significado 'junta de individuos de alguna sociedad política clandestina'. Igualmente, el par de derivados colonial 'lo perteneciente a la colonia' y colonizar 'formar o establecer colonia' no son voces prestadas de otras lenguas pero se refieren a un proceso en el que están implicados otros países y que, según el CORDE, empiezan a documentarse a principios del siglo XIX (p. e. colonial, 1809, José María Quirós, Memoria sobre la situación de la agricultura del virreinato). Esta pareja, junto a otras de las voces de este grupo (constitucional, demócrata, imperar), se podría ver como el reflejo de los cambios políticos de la primera mitad del siglo XIX y de cómo estos han generado la extensión de nuevos términos relativos a ellos.

\subsection{Religiones}

En el sector de las voces de la religión, que se define en el DRAE 1837 como 'ciencia que trata de Dios y sus atributos', no destaca en esta edición, según datos de Sánchez García (2009). Son pocos los términos que se incluyen: bautista 'el que bautiza', episcopado 'el orden y la dignidad del obispo' y la acepción de matrimonio referida al significado de esta voz como 'uno de los siete sacramentos de la iglesia [...]'. En su mayoría, son cultismos (archimandrita del lat. ARCHIMANDRĪTA y este del gr. ę $\chi \mu \alpha \nu \delta \rho i ́ \tau \mathrm{G}_{\varsigma} ;$ bardo del lat. bardus,

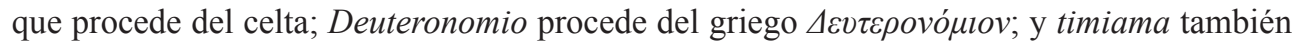

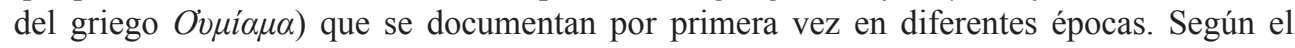
$D E C H$, archimandrita se recoge en Lope, bardo en el siglo XIII y timiama, en Laguna.

Además de los términos relativos al cristianismo, el Diccionario incorpora palabra propias de otras religiones y culturas como el mahometismo (alminar 'torre de las mezquitas 
[...]', aunque podría incluirse quizá también en voces referidas a la arquitectura), el judaísmo (timiama 'entre los judíos confección olorosa reservada al culto divino, castigándose [...]'), la iglesia ortodoxa (archimandrita 'dignidad de la iglesia griega, inferior a la de obispo') y la celta (bardo 'sacerdote y poeta de los antiguos celtas').

\section{NOTA SOBRE LAS VOCES AMERICANAS}

De entre el conjunto de voces y acepciones nuevas incorporadas que se han analizado en los apartados anteriores destaca un grupo que se asocia con América tanto por cuestiones lexicográficas como por sus características semánticas, etimológicas y documentales.

Desde un punto de vista lexicográfico ${ }^{22}$, es interesante advertir que existe un aumento en la inclusión del léxico procedente de Indias, puesto que, desde el Diccionario de autoridades - que presenta un número nada desdeñable de formas americanas en el conjunto de voces provinciales que incluye (Seco 1987: 89) — hasta las ediciones de finales de siglo XIX, la incorporación de americanismos no es notable en la lexicografía académica. De distinto modo actuó la lexicografía no académica principalmente por intereses comerciales (Trujillo-González 2013), en la que destaca por encima de cualquier obra (Seco 1987: 90; Fernández Gordillo 2014: 59), el Nuevo diccionario de la lengua castellana que comprende la última edición íntegra, muy rectificada y mejorada, del publicado por la Academia Española, y unas veinte y seis mil voces, acepciones, frases y locuciones, entre ellas muchas americanas de Vicente Salvá publicado en 1846, cuyo título se refiere ya al número de acepciones americanas y en cuya introducción se menciona que la ausencia de las voces americanas en el diccionario académico es casi total. Por ello, no deja de ser singular que en esta edición, tan poco significativa para la historia del Diccionario (Alvar Ezquerra 1983, 1985, Álvarez de Miranda 2001, Clavería 2016), se encuentren primeras documentaciones de voces americanas en la historia del DRAE tanto en el léxico común como en el especializado.

En una revisión general de los términos, se advierte que se trata de 10 formas léxicas que se corresponden con 8 voces de nueva incorporación (bambú o bambuc, calisaya, chambón, chambonada, cúbica, naboria, quinina, volanta) y 2 acepciones añadidas a voces ya recogidas en la obra antes de la octava edición (poncho, petaca). Estas pertenecen, además, tanto al léxico común de ámbitos semánticos diversos (ropa: cúbica, poncho, cha; juegos: chambón, chambonada; transportes: volanta) como al léxico de especialidad de la historia natural (calisaya, quinina). Asimismo, se advierte que según su procedencia etimológica no se trata de voces de una sola región sino de un conjunto de términos que representan a lugares distintos de la geografía americana. Entre los americanismos se hallan voces de origen -o posible origen, en los casos en los que la etimología no se ha confirmado, como en poncho - náhuatl (petaca), arahuaco (naboria), maratí (bambú), quechua (calisaya, quinina). Para uno de ellos, incluso se proporciona una marca de uso diatópico que lo sitúa en Cuba (volanta, vid. Clavería en prensa).

Son diversas las voces que de este grupo se pueden encontrar documentadas en el Diccionario provincial de voces cubanas de Esteban Pichardo publicado en Matanzas por la Im-

22 Sobre la historia de los indigenismos en la lexicografía anterior al Diccionario de autoridades véase la documentada y resumida introducción de Ariza (2011). 
prenta de la Real Marina que se había publicado en 1836 tan solo un año antes de la octava edición (bambú, chambón, cúbica y volanta) y llama la atención el hecho de que en el final del Prólogo el propio autor se dirija directamente a la Academia para indicarle que puede tomar las que considere oportunas para incluirlas en su Diccionario: "ya si fuese digna de incluirse en el Diccionario general de la Real Academia á semejanza de los provincialismos de Andalucía, Murica \&" (Diccionario provincial de voces cubanas 1836: 5). Véanse en la tabla 13 las cuatro voces que coinciden en ambos repertorios:

\begin{tabular}{|c|c|}
\hline $\begin{array}{l}\text { Diccionario provincial de voces } \\
\text { cubanas (Pichardo 1836) }\end{array}$ & $D R A E(1837)$ \\
\hline $\begin{array}{l}\text { BAMBÚ. N. s. m. vz. ind. Especie } \\
\text { de caña, cuya raiz brota diferentes } \\
\text { tallos cilíndricos, huecos, aunque } \\
\text { interrumpidos por nados proporcionados; } \\
\text { regularmente es de media cuarta el } \\
\text { diámetro de su grueso; sus hojas largas, } \\
\text { delgadas, puntiagudas; sus tallos se } \\
\text { elevan muchísimo adelgazando hácia la } \\
\text { cima por donde se encorvan ó arquean } \\
\text { á manera de plumajes, y enlazandose de } \\
\text { manera que si se forma calle presenta á } \\
\text { la vista una bóveda perfecta y al oído } \\
\text { un susurro agradable. Tiene diferentes } \\
\text { aplicaciones; sus cañutos sirven de } \\
\text { envases para diversos usos; sus hojas } \\
\text { alimento de los animales \&. En la parte } \\
\text { occidental mas comúnmente le llaman } \\
\text { CAÑA BRAVA, y en la centra PITo. [Bambusa } \\
\text { arundinacea.] }\end{array}$ & $\begin{array}{l}\text { BAMBÚ } o ́ \text { BAMBUC. m. Especie de junco nudoso o } \\
\text { caña de Indias que se emplea en bastones y otros usos. }\end{array}$ \\
\hline $\begin{array}{l}\text { CHAMBON, NA. N. adj. fam. Sinónimo } \\
\text { de chapucero. }\end{array}$ & CHAMBON. m. El poco diestro ó torpe en el juego. \\
\hline $\begin{array}{l}\text { CÚBICA. N. s. f. Tela de lana de un } \\
\text { tejido descubierto con que se hacen } \\
\text { casacas, levitas y cosas semejantes. }\end{array}$ & CÚBICA. f. Tela de lana, mas fina que la estameña. \\
\hline $\begin{array}{l}\text { VOLANTE. N. s. f. Una de las especies } \\
\text { de carruajes de lujo usados en la isla, } \\
\text { igual al quitrín, con la diferencia que la } \\
\text { parte superior es firme, á modo de caleza; } \\
\text { cuyo nombre daban antes en tierradentro. } \\
\text { ॥ Véase chUPA. }\end{array}$ & $\begin{array}{l}\text { VOLANTA. f. prov. de la Habana. Especie de calesín } \\
\text { muy ligero. }\end{array}$ \\
\hline
\end{tabular}

Tabla 13. Voces coincidentes en el DRAE 1837 y el Diccionario de voces cubanas de Pichardo (1836).

A pesar de que se puede observar que la definición de algunas de las voces de la octava edición no es la misma que la de la obra de Pichardo (1836), se advierten similitudes que podrían ser indicio de la relación entre ambas obras. Más aún si se toma en cuenta que, se- 
gún datos de Clavería (2016: 110), en las Actas del 15 de octubre de 1835 se explica que se examinan las observaciones de un americano sobre el que no se menciona el nombre. Podría suponerse, quizá, que el número de americanismos incorporado en esta edición mantiene alguna relación con las reflexiones y apuntaciones de este colaborador anónimo.

\section{CONCLUSIÓN}

La investigación que se ha llevado a cabo en las páginas anteriores ha permitido constatar que a pesar de que el $D R A E 1837$ no es una edición en la que se produzcan cambios relevantes ni en cuanto a la técnica y a la metodología lexicográfica se refiere (Álvarez de Miranda 2001, 2003), ni en el aumento de la nomenclatura, muchas de las voces y acepciones que se incorporan son el reflejo del momento histórico (Álvarez de Miranda 2004) en el que la Corporación está inmersa en las tareas de corrección y aumento de la obra.

Desde el punto de vista de la microestructura, como advirtió Vicente Salvá en su versión mejorada del Diccionario de la lengua castellana por la Real Academia Española publicada en 1838, es una edición que presenta una amplia tipología de errores que se produjeron, con toda seguridad, debido a la celeridad con la que los académicos trabajaron para ofrecer una edición después de que la séptima se agotara. La premura con la que se tuvieron que llevar a cabo los trabajos (Clavería 2016) es seguramente también el origen de que el aumento del lemario fuera reducido y de que se recogiera en gran parte en el Suplemento (el 66\% de los nuevos lemas y acepciones que hemos examinado se incluyen en él). Por ello, desde el punto de vista de la macroestructura, es probable que las voces de nueva incorporación fueran también elegidas en un momento en el que quizá no existió la posibilidad de reflexionar y revisar con detenimiento el léxico escogido por la falta de tiempo y ello pudo generar una selección de fuentes más cercanas a la Corporación y sobre las que cabría realizar un estudio más profundo y detallado (Diccionario provincial de voces cubanas de Pichardo, las obras de Benito Jerónimo Feijoo, las poesías de José Somoza, las obras de Leandro Fernández de Moratín, las obras de Manuel Bretón de los Herreros).

El análisis lexicológico de las voces refleja dos cuestiones que permiten advertir una presencia importante de préstamos tanto en el léxico común como en el léxico de especialidad, principalmente procedentes del francés (botasilla, buró, cabriolé, equipo, fagot, jalón, guillotina, guillotinar, tija) o que llegan al español a través del francés como préstamos indirectos de otros idiomas (húngaro: chacó, alemán: chorlo, italiano: collón, neerlandés: colza, griego: higiene, inglés: quechemarín), aunque también tienen presencia otras lenguas europeas como el italiano (brécol, concertante, dueto, arpejio, martelo, violoncelo o violonchelo) y el inglés (frac, cúter, club), además de algunas formas de origen árabe (alminar, bahari, gandul). A este conjunto de incorporaciones hay que añadir todas las nuevas formas y significados de voces ya presentes en la anterior edición que se refieren a realidades propias de otras culturas en ámbitos semánticos diversos (agá, archimandrita, calmuco, ca, cosaco, ca, guanches, teutónico, ca). De entre todo este grupo de adiciones sobresalen las que se refieren a significados propios del español de América (cúbica, poncho, cha, volanta) y a voces de origen amerindio que se corresponden con realidades que se trasladan de un continente a otro (bambú o bambuc, calisaya, naboria, quinina). Además, en esta edición se incorporan palabras que hoy son de uso cotidiano (calcetín, en efectivo, empresario, ria, 
equipo, fumador) además de un conjunto importante de voces de origen culto (acídulo, la, astrágalo, caléndula, convólvulo, escirro, filípica, galvánico, ca, subterfugio).

En esencia, el análisis preliminar que se ha presentado en las páginas anteriores pone de manifiesto que a pesar de que se la ha considerado una edición de poca trascendencia en la historia decimonónica de la lexicografía académica, la octava edición incorpora novedades léxicas de suma relevancia en la historia del español tanto en el léxico común (calcetín, equipo, poncho) como en el léxico especializado (higiene, en efectivo, guillotina) que constituyen el reflejo de la importante presencia de los neologismos y extranjerismos (especialmente de procedencia francesa) en el español de la primera mitad del siglo XIX y de la voluntad de la Corporación por mantener actualizada la obra.

\section{REFERENCIAS BIBLIOGRÁFICAS}

Alvar Ezquerra, M. (1983). "Los prólogos del diccionario académico: nomenclatura específica y microestructura", Revista de Filología Española, LXIII, pp. 33-44.

Alvar Ezquerra, M. (1985): "El diccionario de la Academia a través de sus prólogos: los planteamientos y el vocabulario general", Philologica hispaniensia in honores Manuel Alvar (Lingüística II). Madrid: Gredos, pp. 33-44.

Álvarez de Miranda, P. (2001). "La lexicografía académica de los siglos XVIII y XIX". En Ahumada, I. (coord.): Cinco siglos de lexicografía del español: IV Seminario de Lexicografía Hispánica (Jaén, 17 a 19 de noviembre de 1999). Jaén: Universidad de Jaén, pp. 35-62.

Álvarez de Miranda, P. (2003). "Vicente Salvá, editor y corrector del diccionario de la Academia (1838 y 1841)". En Lexicografia y lexicología en Europa y América. Homenaje a Günther Haensch en su 80 aniversario. Madrid, Gredos, pp. 99-114.

Álvarez de Miranda, P. (2004). "El léxico español, desde el siglo XVIII hasta hoy". En R. Cano Aguilar (coord.), Historia de la lengua española, Barcelona: Ariel, pp. 1037-1064.

Álvarez de Miranda, P. (2009). "Sobre los italianismos en el español del siglo XVIII", Dieciocho: Hispanic enlightenment, 32/4, pp. 19-47.

Ariza Viguera, M. (2011). “A vueltas con los indigenismos americanos del español peninsular”, Itinerarios. Revista de estudios lingüísticos, literarios, históricos y antropológicos, 14, pp. 11-23.

Azorín, D. y R. Baquero (1994-1995). "De la teoría a la práctica lexicográfica: el Nuevo Diccionario de la lengua Castellana de Vicente Salvá”, ELUA, 10, pp. 9-20.

Blanco, M. Á. (2014): "Música entre las letras: el léxico musical de los primeros diccionarios de la RAE". Conferencia inédita pronunciada en la Universitat Autònoma de Barcelona, 28 de noviembre de 2014.

Boyd-Bowman, P. (1971). Léxico hispanoamericano del siglo XVI. London: Tamesis Books Limited.

Buroni, E. (2015). "Ognuno al mondo ha un ramo di pazzia. Rossini a Parigi, Balochi e Il Viaggio a Reims". En Bonomi, I. e V. Coletti (eds.): L'italiano della musica nel mondo, Firenze: Accademia della Crusca, pp. 89-112.

Carriazo Ruiz, J. R. (2018). "Las voces de la navegación: náutica, ingeniería naval y áreas afines". En Clavería, G. y M. Freixas (eds.): El diccionario de la Academia en el siglo XIX: la 5. ${ }^{a}$ edición (1817) al microscopio. Madrid: Arco/Libros, pp. 339-355.

[CDE] M. Davies: Corpus del español [en línea], <http://corpusdelespanol.org>.

$[C D H]$ Instituto de Investigación Rafael Lapesa de la Real Academia Española (2013): Corpus del Nuevo diccionario histórico (CDH) [en linea]. <http://web.frl.es/CNDHE>.

Clavería Nadal, G. (2001). "El léxico del correo en los diccionarios de la Academia Española de la segunda mitad del siglo XIX". En Estudi general: revista de la Facultat de Lletres de la Universitat de Girona, 21, pp. 381-394. 
Clavería Nadal, G. (2003). "La Real Academia Española a finales del siglo XIX: el Diccionario de la

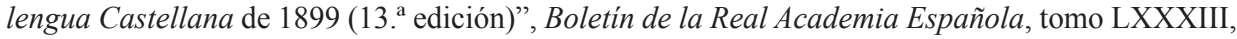
cuaderno 288, pp. 255-336.

Clavería Nadal, G. (2016). De vacunar a dictaminar: la lexicografía académica decimonónica y el neologismo. Madrid/Frankfurt: Iberoamericana Vervuert.

Clavería Nadal, G. (en prensa). "América en el Diccionario de la lengua castellana de la Real Academia Española (1817-1852)", Actas del XII Congreso Internacional de Historia de la lengua española (Lima, agosto 2018).

Contreras Izquierdo, N. (2003): "La lexicografía monolingüe del español en los siglos XIX y XX", Res Diachronicae, 2, pp. 444-452.

[CORDE] Real Academia española: Banco de datos [en línea]. Corpus diacrónico del español. http:// www.rae.es

[DCVB] Alcover, A. M. ${ }^{a}$ y F. de Borja Moll (2002 [1962]): Diccionari català-valencià-balear, Barcelona: Institut d'Estudis Catalans/Editorial Moll. En línea, http://dcvb.iecat.net/.

[DECH] Corominas, J. y J. A. Pascual Rodríguez (1980-1991). Diccionario crítico etimológico castellano e hispánico. Madrid: Gredos.

De Hoyos, J. C. (2007). "Paseo lexicográfico por la economía del Diccionario académico", Pandora: revue d'études hispaniques, 7 , pp. 249-262.

De Hoyos, J. C. (2018). "Las voces de la economía política". En Clavería, G. y M. Freixas (eds.): El diccionario de la Academia en el siglo XIX: la 5. ${ }^{a}$ edición (1817) al microscopio. Madrid: Arco/ Libros, pp. 357-370.

Diccionario de autoridades $=$ Real Academia española (1726-1739). Diccionario de la lengua castellana, en que se explica el verdadero sentido de las voces, su naturaleza y calidad con las phrases o modos de hablar, los proverbios o refranes, y otras cosas convenientes al uso de la lengua. 6 vols., Madrid: Imprenta Francisco del Hierro.

[DICTER] Diccionario de la ciencia y de la técnica del Renacimiento. M Jesús Mancho Duque (dir.), Ediciones Universidad de Salamanca. $<$ http://dicter.usal.es/> [fecha de consulta].

Díez de Revenga, P. (2013). La recepción del discurso científico en la Murcia decimonónica: Tomás Pellicer y Frutos: discurso leído el día 15 de mayo de 2013 en su recepción pública, por la Ilma. Sra. Doña Pilar Díez de Revenga Torres y contestación de la Ilma. Sra. Doña Concepción de la Peña Velasco, Murcia, Real Academia Alfonso X el Sabio.

[DME] O'Scalan, T. (1831). Diccionario maritimo español, que ademas de las definiciones de las voces con sus equivalentes en frances, ingles e italiano, contiene tres vocabularios de estos idiomas con las correspondencias castellanas. Madrid: Imprenta Real.

Fernández Gordillo, L. (2014). "La lexicografía del español y el español hispanoamericano", Andamios: revista de investigación social, 11/26, pp. 53-89.

Fichero General = Real Academia española: Fichero general de la lengua española. [en línea] <http:// web.frl.es/fichero.html>.

Garavaglia, J. C. (2002). "El poncho: una historia multiétnica”. En Boccara, G. (ed.): Colonización, resistencia y mestizaje en las Américas (siglos XVI-XX). Quito: Abya Yala, pp. 185-200.

Garriga Escribano, C. (2001). "Sobre el Diccionario Académico: la 12." ed. (1884)". En Medina Guerra, A. M. ' (coord.): Estudios de lexicografía diacrónica. Málaga, Universidad, págs. 263315.

Garriga Escribano, C. (2003). "La química y la lengua española en el siglo XIX”, Asclepio, 55/2, pp. 93-117.

Gómez de Enterría, J. (1992). "Neología y préstamo en el vocabulario de la economía”, Anuario de estudios filológicos, 15, pp. 97-106.

Gómez de Enterría, J. (1996). Voces de la economía y el comercio en el español del siglo XVIII. Alcalá de Henares: Universidad de Alcalá. 
Gómez de Enterría, J. (2018), "Las voces de las ciencias naturales y áreas afines”. En Clavería, G. y M. Freixas (eds.): El diccionario de la Academia en el siglo XIX: la 5. ${ }^{a}$ edición (1817) al microscopio. Madrid: Arco/Libros, pp. 275-311.

Gutiérrez Rodilla, B. M. (1998). La ciencia empieza en la palabra. Análisis e historia del lenguaje científico. Barcelona: Península.

Grabner, H. (2001). Teoría general de la música. Madrid: Akal.

[GRAE] Real Academia Española (1796). Gramática de la lengua castellana. Madrid: Imprenta de la viuda de Joaquín Ibarra, 4. " edición.

Huertas Martínez, S. (2014). "Suplementos del DRAE (1817-1832): la incorporación de voces de la historia natural”. En Garcés, M. ${ }^{a}$ P. (ed.), Lexicografia especializada: nuevas propuestas. A Coruña: Universidade da Coruña, pp. 87-101.

Hurtado Díaz, A. (2006). “José Somoza, traductor”. En Lafarga, F. y L. Pegenaute (eds.): Traducción $y$ traductores, del Romanticismo al Realismo. Berlin: Peter Lang, pp. 259-269.

Justiniano, J. C. (2014). Las palabras de la música. Las voces relacionadas con la música en el Diccionario de autoridades (1726-1739). Madrid: Universidad Complutense de Madrid. Trabajo de fin Máster.

Justiniano, J. C. (2017). "Las voces de la música, una reflexión previa”, Cuadernos de música iberoamericana, 30, 209-220.

Lapesa, R. (1989). "Palabras y cosas. El vocabulario de la vida social y la indumentaria durante el romanticismo". Estudios. Homenaje al profesor Alfonso Sancho Sáez, I, Granada: Universidad de Granada, pp. 397-412. (Reimpreso en El español moderno y contemporáneo. Estudios lingüísticos, Barcelona: Crítica, 1996, pp. 137-154).

Martínez, M. ${ }^{a}$ A. y M. I. Santamaría (2006): El siglo XIX. Alicante: Biblioteca Virtual Miguel de Cervantes [en línea] <http://www.cervantesvirtual.com/nd/ark:/59851/bmcf4821>.

Mora, D. (2007). "El estudio de algunos vocablos regionales en Argentina durante el siglo XIX". En Ariza, M. et al. (coords.): Actas del II Congreso Internacional de Historia de la Lengua Española. Tomo II, Madrid, Pabellón de España, 1992, pp. 459-468.

Morínigo, M. A. (1955): "Para la etimología de poncho", Nueva Revista de Filología Hispánica, IX, pp. 33-35.

Muñoz Armijo, L. (2012). La historia de los sufijos -ismo e -ista. Evolución morfológica y semántica en la tradición lexicográfica académica española. La Rioja: Cilengua. Fundación San Millán de la Cogolla.

[ORAE 1820] Real Academia Española (1820). Ortografia de la lengua castellana, novena edición, Madrid: Imprenta Real.

[NTLLE] Real Academia Española (2001). Nuevo Tesoro Lexicográfico de la Lengua Española. Madrid: Espasa Calpe [Edición en DVD].

Pérez Pascual, J. I. (2012). “El léxico de especialidad”. En Luque, L., J. F. Medina y R. Luque (eds.): Léxico español III. Venecia: Libreria Editrice Cafoscarina, pp. 189-219.

Prat Sabater, M. (2018). "Los criterios de lematización: los lemas múltiples y la sufijación apreciativa”. En Clavería, G. y M. Freixas (coords.): El diccionario de la Academia en el siglo XIX: la 5. ${ }^{a}$ edición (1817) al microscopio. Madrid: Arco/Libros, pp. 103-113.

Rodríguez Barcia, S. (2013). "El diccionario como producto editorial: estrategias de valorización en los prólogos de los diccionarios académicos de la primera mitad del siglo XIX”, Revista argentina de historiografía lingüistica, V, 1, pp. 27-39.

Sánchez García, F. J. (2009). El léxico religioso en los diccionarios de la Real Academia Española, Barcelona: Universitat de Barcelona.

Sánchez Salas, B. (1999): "Bretón de los Herreros y la Real Academia Española de la Lengua". En Sánchez Salas, B. (ed.): Obra Selecta de Manuel Bretón de los Herreros, vol. 3 (Poesía, Prosa. Bretón académico), La Rioja: Universidad de La Rioja, Instituto de Estudios Riojanos, pp. 363382 . 
Seco, M. (1988). "El léxico hispanoamericano en los diccionarios de la Real Academia Española", Boletín de la Real Academia Española, 68, pp. 85-98.

Štrbáková, R. (2007). Procesos de cambio léxico en el español del siglo XIX: el vocabulario de la indumentaria. Granada: Universidad de Granada, tesis doctoral.

Terreros, E. (1767 [1786-1793]). Diccionario castellano con las voces de ciencias y artes en las tres lenguas francesa, latina é italiana. Madrid: Imprenta de la viuda de Ibarra, hijos y compañía.

[TLF] Centre National de la Recherche Scientifique (2004). Le trésor de la langue française informatisé, Paris: CNRS Éditions [en línea], <http://atilf.atilf.fr/tlf.htm>.

Torruella, J. y S. Huertas (2018). "Las voces de especialidad”. En Clavería, G. y M. Freixas (coords.): El diccionario de la Academia en el siglo XIX: la 5. ${ }^{a}$ edición (1817) al microscopio. Madrid: Arco/ Libros, pp. 253-273.

Trujillo-González, V. (2013). "Los libreros franceses y el desarrollo de la lexicografía española e hispanoamericana del siglo XIX: difusión e influencia”, Études romanes de Brno, 34/2, pp. 9-22. 